Center for

Mathematical Economics

Working Papers

November 2015

\title{
Asymmetric information in a search model with social contacts
}

Yuliia Stupnytska

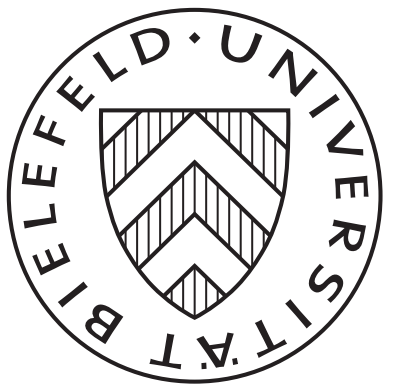




\title{
Asymmetric information in a search model with social contacts
}

\author{
Yuliia Stupnytska*
}

November 6, 2015

\begin{abstract}
In this paper, the search model is proposed, in which homogeneous firms are uncertain about the job seekers' number of friends, who can help them in the job search (social capital). All workers have the same productivity and differ only in the social capital. A firm offers a take-it-or-leave-it wage contract to a worker after checking the worker's profile and her public number of non-fictitious social contacts in the Social Network System in the Internet. This number serves as a noisy signal of the social capital for firms and cannot be influenced by the worker only for signalling purpose. The model generates a positive relationship between the number of contacts in the Social Network System and the wage offered by firms in the equilibrium. In addition, the presence of firm's uncertainty with respect to workers' possibilities to find jobs through social contacts increases overall social welfare.
\end{abstract}

Keywords: social capital, asymmetric information, uncertainty, Social Network System, Facebook, Linkedin, wage contract, wage dispersion, social welfare

JEL Classification: J23, J31, J38, J64 


\section{Introduction}

Uncertainty with respect to worker characteristics is one of the most important problems in the hiring process and has been intensively studied in the literature since the works of Akerlof (1970) and Spence (1973) on asymmetric information about the worker's productivity (for instance, Guash and Weiss (1980), Samuelson (1984), Myerson and Satterthwaite (1983), Alonso (2014)). In addition, there are many recent models studying the issue of asymmetric information in a search-theoretical framework. For example, in their paper, Guerrieri et al. (2010) add search and matching frictions to the classical problems in economies with adverse selection. Kennan (2010) extends the Mortensen and Pissarides (1994) model to allow for private information about the match productivity on the firms' side. Moreover, Bruegemann and Moscarini (2010) investigate the search model with two-sided private information about gains from a match. Related papers are, for example, Dao (2009), Delacroix and Wasmer (2009), Michelacci and Suarez (2006), Acemoglu (1995), Kugler and Saint-Paul (2004).

In addition, there is strong empirical evidence that 30 - $60 \%$ of new employees find jobs through their social contacts (see for example Staiger (1990), Granovetter (1995), Pistaferri (1999), Kugler (2003), Pelizarri (2010), Bentolila et. al. (2010) for different countries). Moreover, the popularity of electronic Social Network Systems (SNS) like LinkedIn, Xing or Facebook in the last decade made it easier to maintain social connections and use them for the job search. ${ }^{1}$ These observations increase the importance of incorporating the social contacts' aspects into the theoretical models of labour market.

Montgomery (1991) is a first theoretical paper which includes both the uncertainty of firms with respect to worker's productivity and the presence of job referrals. In this model, it was found that social contacts' use in the job search may lead to a lower mismatch and therefore, to a higher production efficiency. Due to the pioneering assumption that referrals reveal the quality of the match, also emphasized, for example, in the theoretical paper of Simon and Warner (1992) and approved in the empirical work of Hensvik and Skans (2013), firms with more ability-sensitive technology will hire through social contacts. Therefore, there will be more good matches due to referrals. The classical view in the models on uncertainty not including networks, however, is that asymmetric information generally leads to more inefficiency in the economy (for example, Akerlof (1970), Guerierri et al. (2010), Myerson and Satterthwaite (1983), Bruegemann and Moscarini (2010), Delacroix and Wasmer (2009)). These mixed results, thus, motivate for more research on these issues.

In particular, it would be natural to think, that the presence of firm's uncertainty with respect to workers' possibilities to find jobs through social contacts in addition to the asymmetric information about their productivity will create even larger inefficiency. One of the present paper's main objectives is, thus, to investigate this question, which is novel to the literature. More precisely, this paper studies the consequences of the former uncertainty while allowing the worker's productivity to be the common knowledge for simplicity. Let us now shortly describe the main ingredients of the theoretical model.

In this paper, the random matching model is proposed, in which homogeneous firms face

\footnotetext{
${ }^{1}$ According to Statista (2014), 87\% (23\%) of U.S. Internet users, who are 18-29 years old, $73 \%$ (31\%) of 30-49 years old and $63 \%$ (30\%) of 50-64 years old used Facebook (LinkedIn) in September 2014. Similar numbers are presented also by Pew Research Center (2014). These numbers are larger than in the previous years.
} 
uncertainty about the social capital of job seekers, who have equal productivity and all other observable characteristics. The term social capital denotes the number of actual contacts of a worker, who typically can help her to find a job in addition to her own job search through the formal channel of public offers. Thus, workers who have a larger social capital, have also larger outside options (reservation wage) in terms of job search. This number is known perfectly to workers. For simplicity, only two worker types are considered - with a low and high number of actual contacts. Wages are assumed to be offered only by firms in a form of a take-it-or-leave-it offer during the interview with a job seeker. A worker accepts a wage contract if it is at least as large as her outside options. In addition, wages are set in such a way that workers will have an incentive to exert an endogenous effort which increases the duration of a match.

A firm knows only the distribution of workers' social capital (or of worker types) in the economy and has to offer such a wage contract to a worker, so that she accepts it, otherwise a firm is left with an open vacancy and receives zero profit in the equilibrium. An important feature of the model is that firms also check the worker's profile and her public number of nonfictitious social contacts in the Social Network Systems in the Internet during the interview. This number is assumed to be correlated to the actual number of friends and, therefore, serves as a noisy signal of the social capital for firms when they decide about the wage offer. A worker knows that her profile is being checked. ${ }^{2}$

This ingredient of the model is supported by the recent empirical evidence. For instance, in the nationwide survey in the U.S., which was conducted on behalf of CareerBuilder in February 2013, and included more than 2,100 hiring managers and human resource professionals, it was found that "nearly 39 percent of firms use SNS to research job candidates, up from 37 percent in 2012" (CarreerBuilder.com (2013)) . Among other general personal characteristics of an individual, the firms pay attention, whether the job seeker has great communication skills and whether other people posted great references about the candidate (CarreerBuilder.com (2013)). Moreover, Roulin and Bangerter (2013) find from the 96 HR managers' survey, that recruiters also focus on the number of friends generated by the SNS, since it may reflect the applicants network ${ }^{4}$.

In addition, Bohnert and Ross (2010) have conducted the laboratory experiment, where it was found that the candidates having alcohol-oriented pictures in their profile were offered 7 percent less salary than candidates having family-oriented pictures. At the same time, Utz (2010) proposes a sociological experiment, which shows, that the person's profile, profile pictures of the friends and number of friends jointly influence others' impressions, since the number of contacts is more likely to be manipulated. ${ }^{5}$ Hence, the public number of contacts, which a

\footnotetext{
${ }^{2}$ Vicknair et al. (2010) report that $45.3 \%$ students believe that employers and recruiters look at job candidates' social networking profiles all of the time.

${ }^{3}$ Further, Manant et al. (2014) conduct an experiment with two fictitious Facebook profiles of applicants that differ in their origin, in which they find the strong evidence ( $40 \%$ difference) that employers rely on the online information when deciding to call an applicant back for interview. "IT is the industry using it the most, at a whopping 52 percent. The least? Health care, at 28 percent. Employers are primarily using Facebook (65 percent) and LinkedIn (63 percent) to research candidates" (CarreerBuilder.com (2012)). Employers are using all the tools available to them to assure they make the correct hiring decision, and the use of social media continues to grow", says Rosemary Haefner, vice president of human resources at CareerBuilder (CarreerBuilder.com (2013)).

${ }^{4}$ They also report that professional SNS (e.g., LinkedIn) is perceived as a potential antecedent of Person-Job fit and personal SNS (e.g., Facebook) - of Person-Organization fit.

${ }^{5}$ Therefore, one can conclude, that hiring managers try to get an overall impression about the candidates personality, communal orientation, social attractiveness etc. and about her possibilities to be referred for a job.
} 
firm can look up in an SNS is not necessarily the one generated by the system, but rather the approximate number of contacts who would be ready and able to help the person to find a job from the firm's point of view ${ }^{6}$.

In the present model, it is also assumed for simplicity that all job-seekers have SNS profiles and all firms look them up. Another simplifying assumption is that workers cannot increase their public number of contacts (make the overall impression and social attractiveness better) only for the signalling purpose or, equivalently, firms can identify this manipulation quite easily.

In this paper, there are two wage contracts for simplicity, that are intended at workers with low and high number of actual friends, respectively. A (partially) separating equilibrium is considered, which follows a threshold rule w.r.t. a signal according to a firms' indifference condition. In this equilibrium, the higher wage will be accepted by both worker types and the lower wage only by the low types leading only to partial separation.

The model generates a positive relationship between the number of contacts in the Social Network System in the Internet and the wage offered by firms in the equilibrium. Thus, there will be a wage dispersion between equally productive workers with different number of contacts in the Internet, which extends the classical result on wage dispersion with respect to the signal in the literature on uncertainty about the worker's productivity (see, for example, Spence (1973)) ${ }^{7}$. Moreover, this model gives an additional explanation for the empirically observed log wage dispersion between workers with equal productivity and other observable characteristics of about $70 \%$ (e.g. Mortensen (2003)). In addition, this model is in line with the theoretical literature emphasizing the positive effect of referrals on wages and the wage dispersion due to the difference in the number of social contacts. For instance, such theoretical papers as Montgomery (1992) and Ioannides and Soetevent (2006) incorporate the similar mechanism as in the present paper, namely, that social contacts increase the reservation wage. This positive effect is found also in many empirical works, for example, in Staiger (1990), Simon and Warner (1992), Granovetter (1995), Margolis and Simonnet (2003) and Goos and Salomons (2007) for different countries. Overall, however, the theory and evidence on the effect of social contacts on wages are mixed ${ }^{8}$.

In addition, the comparative statics w.r.t. the firms' uncertainty level increase was conducted. Moreover, the equilibrium outcomes were compared numerically with the two extreme cases: the case of perfect information, when workers' social capital is observed perfectly, and the case of a full information asymmetry, when firms don't have any reliable signal to make inferences about workers' outside options. It was found that (reservation) wages, the overall average firm's profit and average workers' income levels in the benchmark case lead to those arising in the case of a full information asymmetry as the firms' uncertainty level increases. Thus, naturally, the equilibrium outcomes in the asymmetric information case are in between of these two extreme cases.

The overall average workers' income is decreasing since the average workers' income of low

\footnotetext{
${ }^{6}$ Indeed, among adults, on average, $37 \%$ of their total Facebook friends are reported to be actual friends (Ellison et al. (2014)) and, among undergraduate students, 25\% are their actual friends (Ellison et al. (2011)).

${ }^{7}$ The present framework can be easily changed in order to analyze the relationship between the wage offered and the test score during the interview with a worker, where the test score is a noisy signal of a worker's productivity. In this case workers will be different in the productivity, but not in the job-finding rate. The present model, however, aims at analyzing the opposite case, when workers differ in the job-finding rate, but not in the productivity.

${ }^{8}$ Bentolila, Michelacci and Suarez (2010) report wage penalties in the United States and the European Union. This result is supported by Delattre and Sabatier (2007), Pistaferri (1999) as well as Addison and Portugal (2002) for France, Italy and Portugal respectively.
} 
types is increasing slower than that of high types is decreasing. The overall average firms' profit is increasing since the number of vacancies decreases. The overall social welfare is increasing and is larger than those in the two extreme cases for the large level of uncertainty since the overall average firms' profit is increasing faster the overall average workers' income is decreasing. This result may seem counterintuitive.

One of the reasons for this is that firms anticipate that expected profits from an open vacancy will decrease due to more mismatched wages offered and open less vacancies thus decreasing their overall cost and leading to the welfare increase. So the information asymmetry turns out to be welfare improving as firms, by chance, will employ less workers which they would not like to employ. In the standard search theory with perfect information (for example, Pissarides (2000)), the social welfare is maximized when the workers' bargaining power is equal to the elasticity of the job-filling rate. This result is known as the Hosios condition. Otherwise, when their bargaining power is too low (high), firms will open too many (few) vacancies due to low (high) wages leading to more inefficiency. Since in the present model the wage is offered only by firms, the workers' wages are relatively low. This gives an intuition why the social welfare in the perfect information case is not the largest since the Hosios condition is not satisfied.

It is interesting to compare this finding to the conclusion of Montgomery (1991) that social contacts use leads to a higher level of social welfare due to a lower mismatch between firms and workers as referrals reveal the quality of the match. In the present paper, a higher level of mismatched wages offered contributes to the increase in the welfare.

The paper is organized as follows. Section 2 explains notation and the general labour market environment. In section 3 the decisions of workers and firms are investigated and the equilibrium outcome is presented. Section 4 compares the benchmark case of the model to the perfect information case and section 5 compares it to the another extreme case of a full information asymmetry. Section 6 discusses the issue of social welfare comparison between these three cases. Section 7 illustrates the theoretical results and comparative statics by means of a numerical example, while section 8 concludes the paper.

\section{Labour market modeling framework}

The labour market is characterized by the following properties. There is a continuum of infinitely lived risk neutral workers and firms discounting future at a common discount rate $r$. Firms are homogeneous and free to enter the labour market by opening a new vacancy with the flow cost $c$ of travelling and accommodation of job seekers and advertising job offers in the Internet, newspapers, job fairs etc.

All the workers in the economy have the same productivity $y$, but differ only in the number of actual contacts (or social capital), which is their private information in the benchmark case of the model. These contacts may help them in the job search (informal channel) in addition to the formal search in a public job market and therefore, influence their outside options. It is assumed that the search is costless through both channels for simplicity. The matching between workers and firms is random. Wages are assumed to be only offered by firms (take-it-or-leave-it offer) during the interview and a worker accepts the wage contract if it exceeds or is equal to her outside options. For simplicity, let there be only two types of workers: with low and high 
social capital, i.e. with the number of actual contacts $n_{L}$ or $n_{H}$, respectively. They are further also referred to as type $i$ workers, where $i=L, H$. Firms are aware about the values of $n_{L}$ and $n_{H}$ and about the distribution of worker types. Denote the fraction of workers who have a low social capital as $\operatorname{Pr}\left(n_{L}\right)$. Then, the fraction of workers with the high social capital is equal to $\operatorname{Pr}\left(n_{H}\right)=1-\operatorname{Pr}\left(n_{L}\right)$.

Let the total measure of workers be equal to 1 . A worker can be either employed or unemployed. Let $u_{i}$ be the mass of unemployed workers of type $i$ (with $\mu_{i}=u_{i} / \operatorname{Pr}\left(n_{i}\right)$ being their unemployment rate) and $e_{i}$ - the mass of corresponding employed workers in the benchmark case, so that $e_{i}+u_{i}=\operatorname{Pr}\left(n_{i}\right)$. In addition, firms can see the worker's public number of contacts $n_{i}^{\prime}$ in the Social Network Systems in the Internet which is correlated to $n_{i}$ and therefore serves as a noisy signal of $n_{i}$ for firms when they decide about the wage offer during the interview. It is assumed for simplicity that workers cannot increase their number $n_{i}^{\prime}$ only for the signalling purpose.

Moreover, firms intend to provide workers with correct incentives. When employed the worker of a particular type chooses an optimal effort level $g \geq 0$ conditional on the contract wage offered her by the firm. This effort is unobservable to the firm. The cost of exerting effort $g$ is $k(g)$, where it is assumed that $k(0)=0, k^{\prime}(g)>0$. Every firm-worker match is subject to the separation rate $\delta(g)$, which is modeled as a decreasing function of $g\left(\delta^{\prime}(g)<0\right)$ as in Zaharieva (2010) in such a way inducing workers to exert more effort in order to increase the match duration. Let us consider throughout the paper the example when the separation rate $\delta(g)$ takes the following form: $\delta(g)=1 /\left(\sqrt{g}+d_{0}\right)$ (diminishing returns of effort to the job duration). The constant $d_{0}>0$ denotes the minimal job duration corresponding to zero effort. Let also the effort cost function take a usual quadratic form, i.e. $k(g)=k_{0} g^{2}$, where $k_{0}>0$ is a constant multiplier.

Let $m(u, v)$ denote a matching function between workers and firms, where $v$ is the number of open vacancies and $u=\sum_{i} u_{i}$ is the overall number of unemployed workers. For simplicity, let us assume that the matching technology is quadratic, that is $m(u, v)=u v \cdot{ }^{9}$ Consider first the formal search channel. The number of matches between open vacancies and unemployed workers of type $i$ is given by $v u \cdot \frac{u_{i}}{u}=v u_{i}$, meaning that their job-finding rate through this channel of job search is equal to $\frac{v u_{i}}{u_{i}}=v$.

In addition, unemployed workers can hear about open vacancies through their actual social contacts. First, an employee hears about a new job opening at an exogenous rate $a$ per unit time as in Cahuc and Fontaine (2009). Then, this employee transmits the vacancy information to one randomly chosen unemployed friend out of a pool of her actual contacts. Thus, the firm is not aware whether the person has found a job in the formal way or received vacancy information through the network. Let us introduce the additional parameter $\gamma$ denoting the level of homophily between the actual social contacts of a worker, i.e. when $\gamma=1$ all the workers with low (high) number of friends are in contact only with also low (high) types and when $\gamma=0.5$ there is no homophily. In general, for $\gamma \in[0.5,1], \gamma n_{i}$ contacts of a type- $i$ worker are of the same type and $(1-\gamma) n_{i}$ contacts are of the opposite type.

For the special case of the full homophily, $\gamma=1$, the job finding rate of a type- $i$ worker

\footnotetext{
${ }^{9}$ This approach is also used, for example, in Gautier et al. (2010). Moreover, this technology may be, due to Teulings and Gautier (2004), the most adequate assumption in models with heterogeneous workers.
} 
$\lambda_{i}=\operatorname{ave}_{i} \frac{\left[1-\left(1-\mu_{i}\right)^{n_{i}}\right]}{u_{i}}=a v\left(1-\mu_{i}\right) \frac{\left[1-\left(1-\mu_{i}\right)^{n_{i}}\right]}{\mu_{i}}$ as in Stupnytska and Zaharieva (2015). The expression in square brackets is the probability that there is at least one unemployed worker among the $n_{i}$ contacts of an employed worker. This case will be taken as a benchmark throughout the paper for the sake of simplicity. According to Rivera et al. (2010), social networks tend to exhibit a high level of homophily with respect to such characteristics as age, gender, religion, ethnicity, values, intelligence, and education. Indeed, this case may, for instance, capture the situation when foreigners (natives) are more likely to be in contact with other foreigners (natives) and, thus, to be members of a network with low (high) number of contacts. Thus, in this case, the larger is the number of actual contacts of the worker of type $i$ the larger is her $\lambda_{i}$. The expression for $\lambda_{i}$ can be also easily modified for the case of $\gamma<1 .{ }^{10}$

As it is mentioned above, firms don't observe the actual number of contacts $n_{i}$ of a worker but look up the number of contacts $n_{i}^{\prime}$ in the Internet during the interview in order to make an inference about $n_{i}$ (and, hence, about her outside options) and to offer on this basis such a wage contract that a worker of type $i$ will accept. This noisy signal $n_{i}^{\prime}$ is assumed to be correlated to $n_{i}$, i.e. $n_{i}^{\prime}=n_{i}+\epsilon$, where the observation error of the firm $\epsilon$ is normally distributed with the mean 0 and the standard deviation $\sigma_{\epsilon}$, i.e. $N\left(0, \sigma_{\epsilon}^{2}\right)$.

Therefore, a worker with $n_{i}$ actual contacts knows that a firm will draw the number of contacts $n_{i}^{\prime}$ from the conditional distribution with the c.d.f. $F\left(n^{\prime} \mid n_{i}\right)$ and the density $f\left(n^{\prime} \mid n_{i}\right)$ having the mean $n_{i}$ and the standard deviation $\sigma_{\epsilon}$ :

$$
F\left(n^{\prime} \mid n_{i}\right): N\left(n_{i}, \sigma_{\epsilon}^{2}\right)
$$

On the other hand, a firm infers the probability that the unemployed worker has $n_{L}$ actual contacts conditional on the observed signal $n^{\prime}$. It can be found from the Bayes' rule:

$$
\operatorname{Pr}\left(n_{L} \mid n^{\prime}\right)=1-\operatorname{Pr}\left(n_{H} \mid n^{\prime}\right)=\frac{f\left(n^{\prime} \mid n_{L}\right) \cdot \beta}{f\left(n^{\prime} \mid n_{L}\right) \cdot \beta+f\left(n^{\prime} \mid n_{H}\right) \cdot(1-\beta)}
$$

where $\beta=\frac{u_{L}}{u_{L}+u_{H}}$ is the probability that the worker met is of type- $L$ and $1-\beta=\frac{u_{H}}{u_{L}+u_{H}}$ is the probability that this worker is of type- $H$.

Assume for simplicity that, when offering wage contracts, firms follow the threshold rule w.r.t. a signal according to the ex-post indifference condition and then let us check whether

\footnotetext{
${ }^{10}$ Let us denote the type opposite to the type $i$ by $j$. The probability that there is at least one unemployed worker among the $n_{i}$ contacts of a type- $i$ employed worker is equal to $\left[1-\left(1-\mu_{i}\right)^{\gamma n_{i}}\left(1-\mu_{j}\right)^{(1-\gamma) n_{i}}\right]$ as $(1-$ $\left.\mu_{i}\right)^{\gamma n_{i}}\left(1-\mu_{j}\right)^{(1-\gamma) n_{i}}$ is the probability that all her contacts are employed. Let the average unemployment rate in the network of type- $i$ workers be equal to $\bar{\mu}_{i}=\gamma \mu_{i}+(1-\gamma) \mu_{j}$. With the probability $\frac{\gamma \mu_{i}}{\bar{\mu}_{i}}$ the unemployed worker, to whom the vacancy information is transmitted, is also of type $i$ and with the probability $\frac{(1-\gamma) \mu_{j}}{\bar{\mu}_{i}}$ this worker is of the opposite type. The probability that there will be a match between a firm and a given type- $i$ unemployed worker through any of her type- $i$ employed contacts is then equal to ave $e_{i}\left[1-\left(1-\mu_{i}\right)^{\gamma n_{i}}\left(1-\mu_{j}\right)^{(1-\gamma) n_{i}}\right] \frac{\gamma \mu_{i}}{\bar{\mu}_{i}}$. Analogously, the probability that there will be a match between a firm and this worker through any of her type- $j$ employed contacts is then equal to $a_{v e}\left[1-\left(1-\mu_{j}\right)^{\gamma n_{j}}\left(1-\mu_{i}\right)^{(1-\gamma) n_{j}}\right] \frac{(1-\gamma) \mu_{i}}{\bar{\mu}_{j}}$. The job finding rate of a type- $i$ worker, $\lambda_{i}$, through this channel is then the sum of these two expressions divided by $u_{i}$ :$$
\lambda_{i}=a v\left[\left(1-\mu_{i}\right)\left[1-\left(1-\mu_{i}\right)^{\gamma n_{i}}\left(1-\mu_{j}\right)^{(1-\gamma) n_{i}}\right] \frac{\gamma}{\bar{\mu}_{i}}+\left(1-\mu_{j}\right)\left[1-\left(1-\mu_{j}\right)^{\gamma n_{j}}\left(1-\mu_{i}\right)^{(1-\gamma) n_{j}}\right] \frac{(1-\gamma)}{\bar{\mu}_{j}}\right]
$$ 
there will be such a separating equilibrium in this economy. Denote the two wage contracts that are intended at the workers with $n_{L}$ and $n_{H}$ number of actual friends by $w_{L}$ and $w_{H}$, respectively. If the outside options of type- $H$ workers are larger than those of type- $L$ workers only because of the higher job-finding rate for a given wage, the wage $w_{H}$ offered must be larger than $w_{L}$ (which itself must be less than the reservation wage of high types in the separating equilibrium) for the workers with $n_{H}$ contacts to accept. Otherwise, the position which met the high type worker remains vacant and the firm receives zero profit in the equilibrium. Denote the threshold value of the signal $n^{\prime}$, for which firms are indifferent between offering the wage $w_{L}$ and $w_{H}$, by $\bar{n}^{\prime}$. This means that after observing $n^{\prime} \leq \bar{n}^{\prime}$ a firm will offer the wage $w_{L}$ and, in the opposite case, it will offer $w_{H}$. Thus, there will be a positive correlation between the number of contacts in the Social Network System and the wage offered by firms in the equilibrium. In this equilibrium, the wage $w_{H}$ will be accepted by both worker types and the wage $w_{L}$ - only by the low types leading only to partial separation. In order to fully characterize this equilibrium outcome, let us first consider the workers' and then the firms' side.

\section{Analysis of the model}

\subsection{Workers: effort choice}

Consider first the partial equilibrium case when the number of vacancies $v$ is exogenously given. Let $U_{i}$ denote the present value of an unemployed worker of type $i=L, H$ or her outside options. In addition, let $W_{L}$ and $W_{L H}$ denote the asset value of a type- $L$ worker employed at the wage $w_{L}$ and, by the firm's mistake, at the wage $w_{H}$, respectively, and let $W_{H}$ be the present value of a type- $H$ worker employed at wage $w_{H}$.

Both firms and workers are interested in more effort to be exerted on the job, since it increases the match duration, which is profitable for workers as well as for firms as in Zaharieva (2010). Denote the effort level of the type- $i$ worker induced by the wage $w_{i}$ offered as $g_{i}$ and the effort level of type- $L$ worker in response to the wage $w_{H}$ offered as $g_{L H}$ in case when the firm has made a mistake. $W_{i}$ and $W_{L H}$ then also denote the asset values of an employed worker exerting the optimal effort level $g_{i}$ and $g_{L H}$, respectively. The Bellman equations for the employed workers choosing different effort levels can be then written as:

$r W_{i}=\max _{g_{i}}\left\{w_{i}-k\left(g_{i}\right)-\delta\left(g_{i}\right)\left(W_{i}-U_{i}\right)\right\} \quad r W_{L H}=\max _{g_{L H}}\left\{w_{H}-k\left(g_{L H}\right)-\delta\left(g_{L H}\right)\left(W_{L H}-U_{L}\right)\right\}$

Equations (1) show that workers face a tradeoff between the gain from a lower separation rate $\delta(g)$ and the cost of exerting effort $k(g)$. A worker of type $i$ employed at the wage $w_{i}$ maximizes the rent $W_{i}-U_{i}$ w.r.t. $g_{i}$ given $U_{i}$ and a worker of type $L$ employed at the wage $w_{H}$ maximizes the job surplus $\left(W_{L H}-U_{L}\right)$ w.r.t. $g_{L H}$ given $U_{L}$. The first order conditions for these two problems can be written as:

$$
W_{i}-U_{i}=\frac{w_{i}-k\left(g_{i}\right)-r U_{i}}{r+\delta\left(g_{i}\right)}=\left|\frac{k^{\prime}\left(g_{i}\right)}{\delta^{\prime}\left(g_{i}\right)}\right| \quad W_{L H}-U_{L}=\frac{w_{H}-k\left(g_{L H}\right)-r U_{L}}{r+\delta\left(g_{L H}\right)}=\left|\frac{k^{\prime}\left(g_{L H}\right)}{\delta^{\prime}\left(g_{L H}\right)}\right|
$$

Thus, from equations (2) (incentive compatibility constraints) the optimal effort level $g_{i}$ can be expressed as a function of $w_{i}-r U_{i}$ and $g_{L H}$ as a function of $w_{H}-r U_{L}$. Then, analogously to 
Lemma 1 in Zaharieva (2010) one can show that for the convex cost function $k(g), g_{i}\left(g_{L H}\right)$ is increasing in $w_{i}-r U_{i}\left(w_{H}-r U_{L}\right)$ for a given $U_{i}\left(U_{L}\right)$ when $\delta^{\prime \prime}\left(g_{i}\right)<0\left(\delta^{\prime \prime}\left(g_{L H}\right)<0\right)$. Moreover, the optimal effort level $g_{i}\left(g_{L H}\right)$ is equal to 0 when $w_{i}=r U_{i}\left(w_{H}=r U_{L}\right)$. These conditions hold for the assumed functional forms of $k(g)$ and $\delta(g)$.

This mechanism of the optimal effort choice ensures that conditions $W_{i}-U_{i}>0 \Leftrightarrow r U_{i}<$ $w_{i}-k\left(g_{i}\right)$ and, therefore, $r U_{i}<w_{i}$ hold. Hence, for the existence of the semi-separating equilibrium discussed above assume that the condition $w_{L}<r U_{H}$, which prevents high types from accepting the low wage, holds. To summarize, for this equilibrium to exist, the following condition should hold:

$$
r U_{L}<w_{L}<r U_{H}<w_{H}
$$

In the numerical example (section 7 ) it is checked that the condition $w_{L}<r U_{H}$ holds for the realistic parameter values and that it will be indeed optimal for firms to offer wages according to the threshold rule.

All unemployed workers receive the unemployment benefit $z$ and can find a job through the both search channels with the rate $\lambda_{i}+v$ depending on the type. In the equilibrium, workers correctly anticipate the threshold value $\bar{n}^{\prime}$. A type- $L$ unemployed, therefore, expects to be employed at the wage $w_{L}$ when the signal $n^{\prime}$ drawn by the firm is less than $\bar{n}^{\prime}$ and at the wage $w_{H}$ otherwise. The Bellman equation for $U_{L}$ can be, thus, written as follows:

$$
r U_{L}=z+\left(\lambda_{L}+v\right)\left[\operatorname{Pr}\left(n^{\prime} \leq \bar{n}^{\prime} \mid n_{L}\right)\left(W_{L}-U_{L}\right)+\left(1-\operatorname{Pr}\left(n^{\prime} \leq \bar{n}^{\prime} \mid n_{L}\right)\right)\left(W_{L H}-U_{L}\right)\right]
$$

where the probability $\operatorname{Pr}\left(n^{\prime} \leq \bar{n}^{\prime} \mid n_{L}\right)$ is equivalent to $F\left(\bar{n}^{\prime} \mid n_{L}\right)$.

A type- $H$ unemployed accepts only the wage $w_{H}$ in the equilibrium. However, this wage is offered by a firm only when the signal $n^{\prime}$ drawn is larger than $\bar{n}^{\prime}$. The present value of unemployment for the worker with $n_{H}$ contacts can, thus, be written as follows:

$$
r U_{H}=z+\left(\lambda_{H}+v\right)\left(1-\operatorname{Pr}\left(n^{\prime} \leq \bar{n}^{\prime} \mid n_{H}\right)\right)\left(W_{H}-U_{H}\right)
$$

where the probability $\operatorname{Pr}\left(n^{\prime} \leq \bar{n}^{\prime} \mid n_{H}\right)$ is equivalent to $F\left(\bar{n}^{\prime} \mid n_{H}\right)$.

\subsection{Firms: wage determination}

Let $V$ denote the present value of the open vacancy, which will be defined later. In the equilibrium it is equal to 0 (the free-entry condition). Assume that, when choosing wages, firms maximize their ex-ante expected profit (before the realization of a signal) with respect to wages $w_{L}$ and $w_{H}$ and the threshold value of the signal $\bar{n}^{\prime}$ subject to their ex-post indifference condition (after the realization of a signal):

$$
\begin{gathered}
\max _{w_{L}, w_{H}, \bar{n}^{\prime}}\left\{\beta\left(\operatorname{Pr}\left(n^{\prime} \leq \bar{n}^{\prime} \mid n_{L}\right) J_{L}+\operatorname{Pr}\left(n^{\prime}>\bar{n}^{\prime} \mid n_{L}\right) J_{L H}\right)+(1-\beta) \operatorname{Pr}\left(n^{\prime}>\bar{n}^{\prime} \mid n_{H}\right) J_{H}\right\} \\
\text { s.t. } \quad \operatorname{Pr}\left(n_{L} \mid \bar{n}^{\prime}\right) J_{L}=\operatorname{Pr}\left(n_{L} \mid \bar{n}^{\prime}\right) J_{L H}+\left(1-\operatorname{Pr}\left(n_{L} \mid \bar{n}^{\prime}\right)\right) J_{H}
\end{gathered}
$$

Firms take $\beta$ parametrically.

$J_{L}$ denotes the firm's present value of profits from a worker employed at wage $w_{L}$ and therefore exerting the effort level $g_{L}$, which results in the separation rate $\delta\left(g_{L}\right) . J_{H}\left(J_{L H}\right)$ is 
the firm's present value of profits from the high (low) type worker employed at wage $w_{H}$ and, thus, exerting the effort level $g_{H}\left(g_{L H}\right)$. The Bellman equations for $J_{L}, J_{L H}$ and $J_{H}$ can be then written as follows ${ }^{11}$ :

$$
\begin{gathered}
r J_{L}=y-w_{L}-\delta\left(g_{L}\right)\left(J_{L}-V\right) \\
r J_{L H}=y-w_{H}-\delta\left(g_{L H}\right)\left(J_{L H}-V\right) \quad r J_{H}=y-w_{H}-\delta\left(g_{H}\right)\left(J_{H}-V\right)
\end{gathered}
$$

The maximization problem of a firm is intuitive. With probability $\beta \operatorname{Pr}\left(n^{\prime} \leq \bar{n}^{\prime} \mid n_{L}\right)$ the worker met by the firm is of type $L$ and the signal $n^{\prime}$ drawn by the firm is lower than the threshold value $\bar{n}^{\prime}$. In this case, the firm receives the asset value $J_{L}$ from the job filled by the low type worker who gets the wage $w_{L}$. With probability $\beta \operatorname{Pr}\left(n^{\prime}>\bar{n}^{\prime} \mid n_{L}\right)$ the worker met by the firm is of type $L$, but the signal $n^{\prime}$ drawn by the firm is higher than $\bar{n}^{\prime}$. In this case, the firm receives the asset value $J_{L H}$ from the job filled by the low type worker who gets the wage $w_{H}$. With probability $(1-\beta) \operatorname{Pr}\left(n^{\prime} \leq \bar{n}^{\prime} \mid n_{H}\right)$ this worker is of $H$-type and the signal drawn is smaller than $\bar{n}^{\prime}$. In this case, the firm offers the wage $w_{L}$ and is left with an open vacancy (receives zero profit) since the high type will not accept. With probability $(1-\beta) \operatorname{Pr}\left(n^{\prime}>\bar{n}^{\prime} \mid n_{H}\right)$ this worker is of $H$-type and the signal was correctly drawn larger than $\bar{n}^{\prime}$. In this case, the firm receives the asset value $J_{H}$ from the job filled by the high type worker who gets the wage $w_{H}$.

The left hand side of the indifference condition is the ex-post expected profit of a firm (after the realization of a signal) from offering the low wage $w_{L}$ to a worker with a signal $\bar{n}^{\prime}$, which will be accepted only when the worker is a low type. The right hand side is the expected profit from proposing the high wage $w_{H}$ to a worker with a signal $\bar{n}^{\prime}$, which is always accepted. With the probability $\operatorname{Pr}\left(n_{L} \mid \bar{n}^{\prime}\right)$ this worker will be of type $L$ and with the opposite probability - of type $H$.

In the numerical example (section 7 ) the values for optimal $w_{L}, w_{H}$ and $\bar{n}^{\prime}$ are found.

\subsection{Steady-state equations and the free-entry condition}

Denote the number of low types employed at high wage by $e_{L H}$ and at low wage by $e_{L L}$ so that $e_{L L}+e_{L H}=e_{L}$. Expressions for $e_{L H}$ and $e_{L L}$ can be found from the respective steady-state equations:

$$
\begin{gathered}
\dot{e}_{L H}=0=u_{L}\left(\lambda_{L}+v\right)\left(1-\operatorname{Pr}\left(n^{\prime} \leq \bar{n}^{\prime} \mid n_{L}\right)\right)-\delta\left(g_{L H}\right) e_{L H} \\
\dot{e}_{L L}=0=u_{L}\left(\lambda_{L}+v\right) \operatorname{Pr}\left(n^{\prime} \leq \bar{n}^{\prime} \mid n_{L}\right)-\delta\left(g_{L}\right) e_{L L}
\end{gathered}
$$

The mass of unemployed workers with $n_{L}$ actual contacts, $u_{L}$, can find a job with probability $\lambda_{L}+v$ through both search channels and with probability $\left(1-\operatorname{Pr}\left(n^{\prime} \leq \bar{n}^{\prime} \mid n_{L}\right)\right)$ this job pays a high wage due to the firm's mistake. This is the inflow into the state $e_{L H}$. At the same time, the mass of workers of type $L$ employed at a high wage, $e_{L H}$, can loose the job with probability $\delta\left(g_{L H}\right)$. This is the outflow out of this state. On the other hand, with the opposite probability $\operatorname{Pr}\left(n^{\prime} \leq \bar{n}^{\prime} \mid n_{L}\right)$ the job found by these unemployed workers pays a low wage. This forms the inflow into the state $e_{L L}$. Similarly, the mass of workers of type $L$ employed at a low wage, $e_{L L}$, can loose the job with probability $\delta\left(g_{L}\right)$ determining the outflow out of this state.

\footnotetext{
${ }^{11}$ It is easy to see that $g_{L H}$ is always larger than $g_{H}$ in the equilibrium, and therefore, $J_{L H}$ is always larger than $J_{H}$.
} 
The steady-state equation for the number of unemployed low types can be then written as:

$$
\dot{u}_{L}=0=\delta\left(g_{L}\right) e_{L L}+\delta\left(g_{L H}\right) e_{L H}-u_{L}\left(\lambda_{L}+v\right)
$$

The mass of workers of type $L$ employed at a low and high wage, $e_{L L}$ and $e_{L H}$, can loose a job with probabilities $\delta\left(g_{L}\right)$ and $\delta\left(g_{L H}\right)$, respectively, leading to the inflow into the state $u_{L}$. However, the unemployed low types, $u_{L}$, can find any job with probability $\lambda_{L}+v$ through both search channels and form in such a way the outflow out of this state.

Therefore, from these three equations, the expressions for $e_{L L}, e_{L H}$ and $u_{L}$ can be written as:

$$
\begin{gathered}
e_{L L}=\frac{\operatorname{Pr}\left(n_{L}\right) \delta\left(g_{L H}\right)\left(\lambda_{L}+v\right) \operatorname{Pr}\left(n^{\prime} \leq \bar{n}^{\prime} \mid n_{L}\right)}{\left(\lambda_{L}+v\right)\left[\left(1-\operatorname{Pr}\left(n^{\prime} \leq \bar{n}^{\prime} \mid n_{L}\right)\right) \delta\left(g_{L}\right)+\operatorname{Pr}\left(n^{\prime} \leq \bar{n}^{\prime} \mid n_{L}\right) \delta\left(g_{L H}\right)\right]+\delta\left(g_{L}\right) \delta\left(g_{L H}\right)} \\
e_{L H}=\frac{\operatorname{Pr}\left(n_{L}\right) \delta\left(g_{L}\right)\left(\lambda_{L}+v\right)\left(1-\operatorname{Pr}\left(n^{\prime} \leq \bar{n}^{\prime} \mid n_{L}\right)\right)}{\left(\lambda_{L}+v\right)\left[\left(1-\operatorname{Pr}\left(n^{\prime} \leq \bar{n}^{\prime} \mid n_{L}\right)\right) \delta\left(g_{L}\right)+\operatorname{Pr}\left(n^{\prime} \leq \bar{n}^{\prime} \mid n_{L}\right) \delta\left(g_{L H}\right)\right]+\delta\left(g_{L}\right) \delta\left(g_{L H}\right)} \\
u_{L}=\frac{\operatorname{Pr}\left(n_{L}\right) \delta\left(g_{L}\right) \delta\left(g_{L H}\right)}{\left(\lambda_{L}+v\right)\left[\left(1-\operatorname{Pr}\left(n^{\prime} \leq \bar{n}^{\prime} \mid n_{L}\right)\right) \delta\left(g_{L}\right)+\operatorname{Pr}\left(n^{\prime} \leq \bar{n}^{\prime} \mid n_{L}\right) \delta\left(g_{L H}\right)\right]+\delta\left(g_{L}\right) \delta\left(g_{L H}\right)}
\end{gathered}
$$

On the other hand, the steady-state equation for workers with $n_{H}$ actual contacts can be written as follows:

$$
\dot{u}_{H}=0=\left(\operatorname{Pr}\left(n_{H}\right)-u_{H}\right) \delta\left(g_{H}\right)-u_{H}\left(\lambda_{H}+v\right)\left(1-\operatorname{Pr}\left(n^{\prime} \leq \bar{n}^{\prime} \mid n_{H}\right)\right)
$$

The mass of employed workers of type $H$ can loose a job with probability $\delta\left(g_{H}\right)$ leading to the inflow into the state $u_{H}$. However, the unemployed high types can find a job with probability $\lambda_{L}+v$ through both search channels and accept it with probability $\left(1-\operatorname{Pr}\left(n^{\prime} \leq \bar{n}^{\prime} \mid n_{H}\right)\right)$ when a high wage is offered. This determines the outflow out of this state. Thus, the number of unemployed type- $H$ workers, $u_{H}$, is equal to:

$$
u_{H}=\frac{\operatorname{Pr}\left(n_{H}\right) \delta\left(g_{H}\right)}{\left(\lambda_{H}+v\right)\left(1-\operatorname{Pr}\left(n^{\prime} \leq \bar{n}^{\prime} \mid n_{H}\right)\right)+\delta\left(g_{H}\right)}
$$

Finally, a present value of an open vacancy denoted by $V$ can be defined as follows. To fill an open vacancy, firms are also using both search channels at the same time. At rate $q_{i}=\lambda_{i} u_{i} / v=$ $\operatorname{aPr}\left(n_{i}\right)\left(1-\mu_{i}\right)\left[1-\left(1-\mu_{i}\right)^{n_{i}}\right]$ a match between a firm and an unemployed worker of type $i$ is formed due to her social contacts and at rate $u_{i}$ the firm is matched with an unemployed worker of type $i$ through a formal channel. Since firms don't know the worker's type and whether the worker has found a job in a formal way or through the network information transmission, they expect to be matched with some unemployed worker with a rate $q_{L}+q_{H}+u$. Then, with probability $\beta$ this will be a low type. The firm will offer her the wage $w_{L}$ with probability $\operatorname{Pr}\left(n^{\prime} \leq \bar{n}^{\prime} \mid n_{L}\right)$ and the wage $w_{H}$ with the opposite probability, and a worker will always accept. On the other hand, with probability $1-\beta$ this will be a worker of high type, and a firm will employ her at a wage $w_{H}$ only with probability $\operatorname{Pr}\left(n^{\prime}>\bar{n}^{\prime} \mid n_{H}\right)$, i.e. when it infers her type 
correctly. The asset value of an open vacancy is then equal to:

$$
\begin{gathered}
r V=0=-c+\left(q_{L}+q_{H}+u\right)\left[\beta\left(\operatorname{Pr}\left(n^{\prime} \leq \bar{n}^{\prime} \mid n_{L}\right)\left(J_{L}-V\right)+\left(1-\operatorname{Pr}\left(n^{\prime} \leq \bar{n}^{\prime} \mid n_{L}\right)\right)\left(J_{L H}-V\right)\right)+\right. \\
\left.+(1-\beta)\left(1-\operatorname{Pr}\left(n^{\prime} \leq \bar{n}^{\prime} \mid n_{H}\right)\right)\left(J_{H}-V\right)\right]
\end{gathered}
$$

The expression in the square brackets is the expected profit of a firm from the maximization problem (6). Hence the optimal firm strategy is chosen so that it maximizes the present value of a vacancy $V$. In the equilibrium, $V$ is equal to 0 (the free entry condition). This allows us to find the last equilibrium variable, the number of vacancies $v$ entering through the unemployment rates. Thus, the described equilibrium can be formally defined in a following way:

Definition 1. Search equilibrium with asymmetric information and with the partial separation of types is a vector of variables $\left(U_{i}, W_{i}, W_{L H}, J_{i}, J_{L H}, g_{i}, g_{L H}, \bar{n}^{\prime}, w_{i}, \mu_{i}, e_{L L}, e_{L H}\right), i=L, H$ as well as the number of vacancies $v$ and the present value of an open vacancy $V$, satisfying the asset value equations for workers (4), (5) and (1), for firms (8) and (9), the firm's maximization problem (6), the optimal effort equations (2), the steady-state conditions (10), (11), (12) and (13), the condition (3) and the free-entry condition $V=0$.

In the numerical example (section 7 ) it is checked that this equilibrium exists for the realistic parameter values.

\section{Perfect information case}

Let us now compare the equilibrium outcomes in a model with asymmetric information from the previous section to those arising in the situation when firms are perfectly informed about the worker type, i.e. when $\sigma_{\epsilon}=0$. When the actual number of contacts is observed perfectly, the wage $w_{i}^{1}, i=L, H$, inducing the optimal effort level $g_{i}^{1}$ is offered to the workers with $n_{i}$ actual contacts, which they always accept. To characterize these equilibrium variables, let us consider the workers' and the firms' side for the case of perfect information.

Let $v^{1}$ be the number of open vacancies in this case. Hence, analogously to the asymmetric information case, the job-finding rate through the formal channel is now equal to $v^{1}$. In addition, let $u_{i}^{1}$ and $e_{i}^{1}$ denote the amounts of unemployed and employed workers of type $i$, respectively, so that $u_{i}^{1}+e_{i}^{1}=\operatorname{Pr}\left(n_{i}\right)$ and the unemployment rate of a worker of this type $\mu_{i}^{1}=u_{i}^{1} / \operatorname{Pr}\left(n_{i}\right)$. Let the overall number of unemployed in this case be $u^{1}=\sum_{i} u_{i}^{1}$. Then, the job finding rate through the social contacts' channel is equal in this case to:

$$
\lambda_{i}^{1}=a v^{1}\left(1-\mu_{i}^{1}\right) \frac{\left[1-\left(1-\mu_{i}^{1}\right)^{n_{i}}\right]}{\mu_{i}^{1}}
$$

Hence, the equation for the present value of unemployment for type $i$ workers can be written in this case similarly to the equation for $U_{i}$ as follows:

$$
r U_{i}^{1}=z+\left(\lambda_{i}^{1}+v^{1}\right)\left(W_{i}^{1}-U_{i}^{1}\right)
$$

where, analogously to $W_{i}$ for the case of asymmetric information, $W_{i}^{1}$ denotes the asset value 
of employment at the wage $w_{i}^{1}$ for the workers with $n_{i}$ actual contacts and is equal to:

$$
r W_{i}^{1}=\max _{g_{i}^{1}}\left\{w_{i}^{1}-k\left(g_{i}^{1}\right)-\delta\left(g_{i}^{1}\right)\left(W_{i}^{1}-U_{i}^{1}\right)\right\}
$$

Thus, from the first order conditions, one can show that the optimal effort level chosen by type $i$ workers, $g_{i}^{1}$ is a function of $w_{i}^{1}-r U_{i}^{1}$ with the similar properties as $g_{i}$, i.e.:

$$
W_{i}^{1}-U_{i}^{1}=\frac{w_{i}^{1}-k\left(g_{i}^{1}\right)-r U_{i}^{1}}{r+\delta\left(g_{i}^{1}\right)}=\left|\frac{k^{\prime}\left(g_{i}^{1}\right)}{\delta^{\prime}\left(g_{i}^{1}\right)}\right|
$$

From the point of view of the firms, let $V^{1}$ denote the present value of the open vacancy, defined later. Moreover, let $J_{i}^{1}$ denote the firm's present value from hiring the type $i$ worker at wage $w_{i}^{1}$ and, thus, inducing the effort level $g_{i}^{1}$ leading to the separation rate $\delta\left(g_{i}^{1}\right)$. The Bellman equation for $J_{i}^{1}$ can be then written as follows:

$$
r J_{i}^{1}=y-w_{i}^{1}-\delta\left(g_{i}^{1}\right)\left(J_{i}^{1}-V^{1}\right)
$$

The values of $w_{L}^{1}$ and $w_{H}^{1}$ offered by firms can be found from the firm's expected profit maximization problem:

$$
\max _{w_{L}^{1}, w_{H}^{1}}\left\{\beta^{1} J_{L}^{1}+\left(1-\beta^{1}\right) J_{H}^{1}\right\}
$$

where $\beta^{1}$ is the analogue of $\beta$ for the perfect information case. Firms take $\beta^{1}$ parametrically. Thus, the solution to this problem gives rise to the following Proposition:

Proposition 1. The wage $w_{i}^{1}, i=L, H$ offered by firms is equal to:

$$
w_{i}^{1}=y-\frac{\left(r+\delta\left(g_{i}^{1}\right)\right)^{2}\left(k^{\prime \prime}\left(g_{i}^{1}\right) \delta^{\prime}\left(g_{i}^{1}\right)-\delta^{\prime \prime}\left(g_{i}^{1}\right) k^{\prime}\left(g_{i}^{1}\right)\right)}{\delta^{\prime}\left(g_{i}^{1}\right)^{3}}
$$

Proof: Appendix I.

Since this wage is always accepted by a worker with $n_{i}$ number of contacts, the steady-state condition for this worker type can be written as follows:

$$
\dot{u}_{i}^{1}=0=\left(\operatorname{Pr}\left(n_{i}\right)-u_{i}^{1}\right) \delta\left(g_{i}^{1}\right)-u_{i}^{1}\left(\lambda_{i}^{1}+v^{1}\right)
$$

Therefore the unemployment rate of type $i$ workers, $\mu_{i}^{1}$, is equal to:

$$
\mu_{i}^{1}=\frac{\delta\left(g_{i}^{1}\right)}{\lambda_{i}^{1}+v^{1}+\delta\left(g_{i}^{1}\right)}
$$

To find the last equilibrium variable, the number of vacancies $v^{1}$ from the free-entry condition, let us define a present value of an open vacancy $V^{1}$ analogously to $V$ from the previous section. The job-filling rate through the social contacts in this case, $q_{i}^{1}$, is the analogue of $q_{i}$ and is equal to $\lambda_{i}^{1} u_{i}^{1} / v^{1}$. When a worker met is of low type (with probability $\beta^{1}$ ), a firm will always figure it out correctly and offer her the wage $w_{L}^{1}$. On the other hand, when a firm meets a worker of high type (with probability $1-\beta^{1}$ ), it offers her the wage $w_{H}^{1}$. The asset value of an open vacancy 
in the perfect information case is then equal to:

$$
r V^{1}=0=-c+\left(q_{L}^{1}+q_{H}^{1}+u^{1}\right)\left(\beta^{1} J_{L}^{1}+\left(1-\beta^{1}\right) J_{H}^{1}\right)
$$

Thus, the perfect information equilibrium can be formally defined in a following way:

Definition 2. Search equilibrium with perfect information is a vector of variables $\left(U_{i}^{1}, W_{i}^{1}\right.$, $\left.J_{i}^{1}, V^{1}, g_{i}^{1}, w_{i}^{1}, \mu_{i}^{1}, v^{1}\right), i=L, H$, satisfying the asset value equations for workers (14) and (15), for firms (17), the wage determination equation (18), the optimal effort equations (16), the steady-state conditions (19) and the free-entry condition $V^{1}=0$.

This equilibrium is the special case of the equilibrium in the asymmetric information case for $\sigma_{\epsilon}=0$. In section 7 below, it is checked that this equilibrium exists for the realistic parameter values and the equilibrium outcomes in the perfect and asymmetric information case are numerically compared.

\section{Case of a full information asymmetry}

This section now compares the benchmark model with asymmetric information to the other extreme case when firms do not have any reliable signal about the worker type, i.e. when $\sigma_{\epsilon} \rightarrow \infty$. This is the case of a full information asymmetry. In this case, the only one wage $w^{0}$ is offered by firms to all workers, which induces the workers with $n_{i}, i=L, H$ actual contacts to exert the optimal effort level $g_{i}^{0}$.

Let $v^{0}$ be the number of open vacancies in this case. Hence, analogously to the benchmark case, the job-finding rate through the formal channel is now equal to $v^{0}$. In addition, let $u_{i}^{0}$ and $e_{i}^{0}$ denote the amounts of unemployed and employed workers of type $i$, respectively, so that $u_{i}^{0}+e_{i}^{0}=\operatorname{Pr}\left(n_{i}\right)$ and the unemployment rate of a worker of this type $\mu_{i}^{0}=u_{i}^{0} / \operatorname{Pr}\left(n_{i}\right)$. Let the overall number of unemployed in this case be $u^{0}=\sum_{i} u_{i}^{0}$. Then, the job finding rate through the social contacts' channel is equal in this case to:

$$
\lambda_{i}^{0}=a v^{0}\left(1-\mu_{i}^{0}\right) \frac{\left[1-\left(1-\mu_{i}^{0}\right)^{n_{i}}\right]}{\mu_{i}^{0}}
$$

Hence, the expression for the present value of unemployment for type $i$ workers, $U_{i}^{0}$, can be written in this case similarly to the equation for $U_{i}$ as follows:

$$
r U_{i}^{0}=z+\left(\lambda_{i}^{0}+v^{0}\right)\left(W_{i}^{0}-U_{i}^{0}\right)
$$

where, analogously to $W_{i}$ for the case of asymmetric information, $W_{i}^{0}$ denotes the asset value of employment at the wage $w^{0}$ for the workers with $n_{i}$ actual contacts and is equal to:

$$
r W_{i}^{0}=\max _{g_{i}^{0}}\left\{w^{0}-k\left(g_{i}^{0}\right)-\delta\left(g_{i}^{0}\right)\left(W_{i}^{0}-U_{i}^{0}\right)\right\}
$$

Thus, from the first order conditions, one can show that the optimal effort level chosen by 
type $i$ workers, $g_{i}^{0}$ is a function of $w^{0}-r U_{i}^{0}$ with the similar properties as $g_{i}$, i.e.:

$$
W_{i}^{0}-U_{i}^{0}=\frac{w^{0}-k\left(g_{i}^{0}\right)-r U_{i}^{0}}{r+\delta\left(g_{i}^{0}\right)}=\left|\frac{k^{\prime}\left(g_{i}^{0}\right)}{\delta^{\prime}\left(g_{i}^{0}\right)}\right|
$$

From the point of view of the firms, let $V^{0}$ denote the present value of the open vacancy, defined later. Moreover, let $J_{i}^{0}$ denote the firm's present value from hiring the type $i$ worker and, thus, inducing the effort level $g_{i}^{0}$. The Bellman equation for $J_{i}^{0}$ can be then written as follows:

$$
r J_{i}^{0}=y-w^{0}-\delta\left(g_{i}^{0}\right)\left(J_{i}^{0}-V^{0}\right)
$$

The steady-state condition for this worker type can be written as follows:

$$
\dot{u}_{i}^{0}=0=\left(\operatorname{Pr}\left(n_{i}\right)-u_{i}^{0}\right) \delta\left(g_{i}^{0}\right)-u_{i}^{0}\left(\lambda_{i}^{0}+v^{0}\right)
$$

Therefore the unemployment rate of type $i$ workers, $\mu_{i}^{0}$, is equal to:

$$
\mu_{i}^{0}=\frac{\delta\left(g_{i}^{0}\right)}{\lambda_{i}^{0}+v^{0}+\delta\left(g_{i}^{0}\right)}
$$

The value of $w^{0}$ offered by a firm which has met the type $i$ worker can be found from the firm's expected profit maximization problem:

$$
\max _{w^{0}}\left\{\beta^{0} J_{L}^{0}+\left(1-\beta^{0}\right) J_{H}^{0}\right\}
$$

where $\beta^{0}$ is the analogue of $\beta$ for the case of a full information asymmetry. Firms take $\beta^{0}$ parametrically.

The solution to this maximization problem gives rise to the following Proposition:

Proposition 2. Let $x^{0}\left(g_{i}^{0}\right)=\left(k^{\prime \prime}\left(g_{i}^{0}\right) \delta^{\prime}\left(g_{i}^{0}\right)-\delta^{\prime \prime}\left(g_{i}^{0}\right) k^{\prime}\left(g_{i}^{0}\right)\right)\left(r+\delta\left(g_{i}^{0}\right)\right)^{3}$, where $i=L, H$. Then, the wage $w^{0}$ offered by firms is equal to:

$$
w^{0}=y-\frac{x^{0}\left(g_{L}^{0}\right) x^{0}\left(g_{H}^{0}\right) \cdot\left[\frac{\beta^{0}}{r+\delta\left(g_{L}^{0}\right)}+\frac{\left(1-\beta^{0}\right)}{r+\delta\left(g_{H}^{0}\right)}\right]}{\beta^{0}\left(\delta^{\prime}\left(g_{L}^{0}\right)\right)^{3} x^{0}\left(g_{H}^{0}\right)+\left(1-\beta^{0}\right)\left(\delta^{\prime}\left(g_{H}^{0}\right)\right)^{3} x^{0}\left(g_{L}^{0}\right)}
$$

Proof: Appendix II.

To find the last equilibrium variable, the number of vacancies $v^{0}$, from the free-entry condition, let us define a present value of an open vacancy $V^{0}$ analogously to $V^{1}$ from the previous section. The job-filling rate through the social contacts in this case, $q_{i}^{0}$, is the analogue of $q_{i}^{1}$ and is equal to $\lambda_{i}^{0} u_{i}^{0} / v^{0}$. The asset value of an open vacancy in this case is then equal to:

$$
r V^{0}=0=-c+\left(q_{L}^{0}+q_{H}^{0}+u^{0}\right)\left(\beta^{0} J_{L}^{0}+\left(1-\beta^{0}\right) J_{H}^{0}\right)
$$

Thus, the equilibrium with a full information asymmetry can be formally defined in a following way: 
Definition 3. Search equilibrium with a full information asymmetry is a vector of variables $\left(U_{i}^{0}, W_{i}^{0}, J_{i}^{0}, V^{0}, g_{i}^{0}, \mu_{i}^{0}, v^{0}\right), i=L, H$, as well as the wage offer $w^{0}$, satisfying the asset value equations for workers (20) and (21), for firms (23), the wage determination equation (25), the optimal effort equations (22), the steady-state conditions (24) and the free-entry condition $V^{0}=0$.

In section 7 below, it is checked that this equilibrium exists for the realistic parameter values and these equilibrium outcomes are also numerically compared with those in the perfect and asymmetric information cases.

\section{Social welfare comparison}

The natural question in this model is, in which of the three cases considered above the overall social welfare as well as workers' income and firms' profits are larger. First, denote by $\Lambda_{W L}$ $\left(\Lambda_{W H}\right)$ the average income of low (high) type workers so that $\Lambda_{W}=\Lambda_{W L}+\Lambda_{W H}$ is the average income of all workers. More precisely, these variables are defined as follows:

$$
\Lambda_{W L}=\left(w_{L}-k\left(g_{L}\right)\right) e_{L L}+\left(w_{H}-k\left(g_{L H}\right)\right) e_{L H}+z u_{L} \quad \Lambda_{W H}=\left(w_{H}-k\left(g_{H}\right)\right) e_{H}+z u_{H}
$$

The average income of low types is equal to the sum of their wages net of the effort cost at low and high wage jobs when employed plus the utility of unemployed workers of this type. Analogously, the average income of high types is their wage net of the effort cost when employed plus the utility of unemployed workers of this type. In addition, let $\Lambda_{F}$ be the average profit of all firms, defined as:

$$
\Lambda_{F}=\left(y-w_{L}\right) e_{L L}+\left(y-w_{H}\right)\left(e_{L H}+e_{H}\right)-c v
$$

It is equal to the firms' profits after hiring low types at both wage contracts and high types at a high wage contract minus the cost of vacancies' creation. It is then easy too see that $\Lambda_{W}+\Lambda_{F}=\Lambda$, which is the overall social welfare level.

Analogously, let us define variables similar to $\Lambda_{W L}, \Lambda_{W H}, \Lambda_{W}, \Lambda_{F}$ and $\Lambda$ for the perfect information case and the case of a full information asymmetry with upper indexes 1 and 0 , respectively. Expressions for average incomes of low and high types in the perfect information case, $\Lambda_{W L}^{1}$ and $\Lambda_{W H}^{1}$, respectively, can be written as follows:

$$
\Lambda_{W L}^{1}=\left(w_{L}^{1}-k\left(g_{L}^{1}\right)\right) e_{L}^{1}+z u_{L}^{1} \quad \Lambda_{W H}^{1}=\left(w_{H}^{1}-k\left(g_{H}^{1}\right)\right) e_{H}^{1}+z u_{H}^{1}
$$

Intuitively, the average income of low (high) type workers in the perfect information case is equal to the low (high) wage net of the low (high) effort cost when employed plus the utility of unemployed low (high) types. Expressions for average incomes of low and high types in the case of the full information asymmetry, $\Lambda_{W L}^{0}$ and $\Lambda_{W H}^{0}$, respectively, can be written analogously as follows:

$$
\Lambda_{W L}^{0}=\left(w^{0}-k\left(g_{L}^{0}\right)\right) e_{L}^{0}+z u_{L}^{0} \quad \Lambda_{W H}^{0}=\left(w^{0}-k\left(g_{H}^{0}\right)\right) e_{H}^{0}+z u_{H}^{0}
$$

Similarly, the average income of low (high) type workers in the case of the full information asymmetry is equal to the wage $w^{0}$ net of the low (high) effort cost when employed plus the 
utility of unemployed low (high) types. Expressions for average profits of firms in the perfect information case and in the case of the full information asymmetry, $\Lambda_{F}^{1}$ and $\Lambda_{F}^{0}$, respectively, can be written as follows:

$$
\Lambda_{F}^{1}=\left(y-w_{L}^{1}\right) e_{L}^{1}+\left(y-w_{H}^{1}\right) e_{H}^{1}-c v^{1} \quad \Lambda_{F}^{0}=\left(y-w^{0}\right)\left(e_{L}^{0}+e_{H}^{0}\right)-c v^{0}
$$

$\Lambda_{F}^{1}$ equals to the firms' profits after hiring low and high types at low and high wage, respectively, minus the cost of vacancies' creation. Analogously, $\Lambda_{F}^{0}$ is equal to the firms' profits after hiring workers at the wage $w^{0}$, minus the cost of vacancies' creation.

Similarly, the average incomes of all workers in the perfect information case and in the case of a full information asymmetry are $\Lambda_{W L}^{1}+\Lambda_{W H}^{1}=\Lambda_{W}^{1}$ and $\Lambda_{W L}^{0}+\Lambda_{W H}^{0}=\Lambda_{W}^{0}$, respectively. Moreover, the overall social welfare levels in cases of perfect information and a full information asymmetry are $\Lambda_{W}^{1}+\Lambda_{F}^{1}=\Lambda^{1}$ and $\Lambda_{W}^{0}+\Lambda_{F}^{0}=\Lambda^{0}$, respectively.

In section 7 below, the overall social welfare levels, average income levels of workers and average profits of firms in the asymmetric information, perfect information and full information asymmetry case will be numerically compared.

\section{$7 \quad$ Numerical example}

\subsection{Calibration}

This section parameterizes the model to match the average labour market indicators in the OECD countries. Let the productivity parameter $y$ be normalized to 1 . A unit period of time in the model is chosen to be six months and the discount rate $r$ is set to 0.01 , which is equivalent to the annual discount rate of $2 \%$. Next, the flow value of leisure $z$ is equal to 0.5 , which is in the middle range of values in the literature. Shimer (2005) sets this value to 0.4, while Fontaine (2008) uses the value of 0.15 for the U.S. economy and 0.4 for the French economy. Gautier (2002) and Cahuc and Fontaine (2009) set $z$ equal to 0.2. On the other hand, Hall and Milgrom (2008) obtain a larger value of 0.71 . The cost of an open vacancy $c$ is chosen to be 0.5 and is also close to the average in the literature. Hagedorn and Manovskii (2008) set the value of 0.58 for this parameter, while Cahuc and Fontaines (2009) value is 0.4. Shimer (2005) has chosen the value of 0.213 for the cost of vacancies while Fontaine (2008) uses the value of 0.3.

Let the number of actual contacts of type- $L$ workers who can help in the job search be equal to 50 and that of type $H$ - to 90 . These choices are in the middle range of numbers in the literature. First, Ellison et al. (2014) report that, for adults in 2011, the mean number of actual friends among their Facebook contacts was 76 out of the 207 total Facebook contacts on average (37\% are actual friends). Tong et al. (2008) report the mean of 395 total Facebook contacts for undergraduate students. According to Statista (2014), the average number of Facebook friends for all age groups is 350. Moreover, Ellison et al. (2011) report that, for undergraduate students, the average fraction of actual friends on Facebook is $25 \%$. Thus, considering relatively younger generations, the average numbers of Facebook contacts of low and high types are equal to $50 / 0.25=200$ and $90 / 0.25=360$, respectively. In addition, let the fraction of type $L$ workers, $\operatorname{Pr}\left(n_{L}\right)$, be equal to 0.5 for easier comparability. Moreover, Rostila (2013) reports that the percentage of people with poor social contacts varies between $21.7 \%$ and $65.1 \%$ for different 
education levels in European countries. Then, the average numbers of actual and Facebook friends are equal to 70 and 280, respectively. These numbers are naturally a bit lower than those in the literature since not all contacts usually help in the job search, in particular, workers of the same profession tend to help more. Cingano and Rosolia (2012) find that the median number of only professional contacts in Italy is equal to 32. This number is higher in Germany and is equal to 43 (Glitz, 2013). At the same time, the mean number of actual contacts is equal to 50 in Cahuc and Fontaine (2009). Fontaine (2008) uses the number of 40 in a benchmark model of his paper. Thus, 70 is a reasonable estimation for an average number of actual contacts who can help to find a job. Moreover, let the standard deviation for the firms' error $\sigma_{\epsilon}$ take the value of 10 in the benchmark case so that, for low types, a firm can receive a signal approximately between 0 and 100 and, for high types, between 40 and 140 as on figure 1 (right panel). This value is the maximal one for the signal to be positive in most of cases.
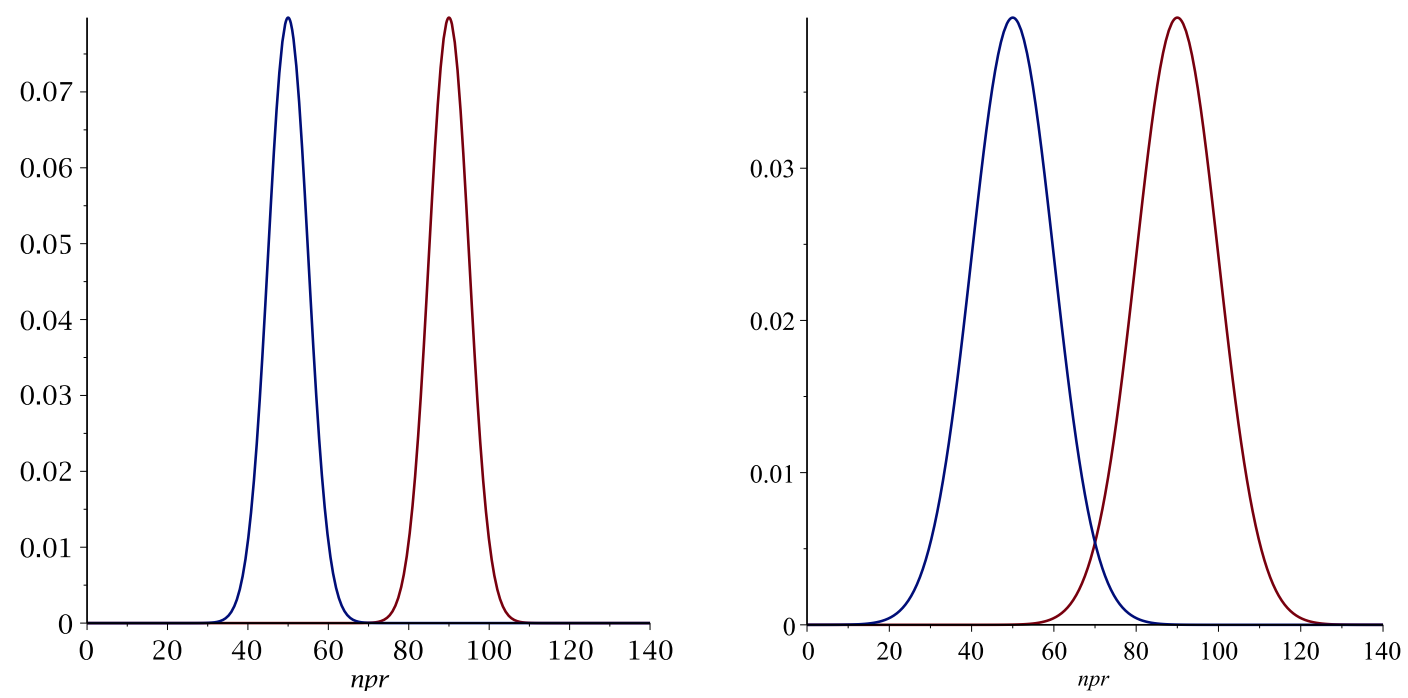

Figure 1: The densities $f\left(n^{\prime} \mid n_{L}\right)$ (blue) and $f\left(n^{\prime} \mid n_{H}\right)$ (red) for $n_{L}=50$ and $n_{H}=90 . \sigma_{\epsilon}=5$ (left) and $\sigma_{\epsilon}=10$ (right).

In addition let the rate $a$ with which employees hear about job vacancies be equal to 0.5. This number is chosen for the average equilibrium job-finding rate to be close to values in the literature. Hobijn und Sahin (2009) report using OECD (2006) "Employment and Labour Market Statistics" that the highest monthly job-finding rate is in the U.S. and is equal to $56.3 \%$, while the lowest one is in Italy, $2.58 \%$. Therefore, the annual job finding rate varies between $0.00258 \cdot 12=0.03$ and $0.563 \cdot 12=6.75$. Parameter $d_{0}$ is set to 5 so that $\delta(0)=1 / 5=0.2$. This value corresponds to the average job duration without effort of $1 /(2 \cdot 0.2)=2.5$ years and is close to the minimal value in the literature. Hall and Milgrom (2008) set the value of $3 \%$ per month, so the average job duration is $1 /(12 \cdot 0.03)=2.78$ years. Pissarides $(2009)$ and Shimer (2005) choose the value of $\delta$ equal to 0.1 for a unit of time being a quarter. This corresponds to the average job duration of $1 /(4 \cdot 0.1)=2.5$ years. Hobijn and Sahin $(2009)$ report a value of $2.3 \%$ per month, so the average job duration becomes $1 /(12 \cdot 0.023)=3.6$ years. Let also $k_{0}>0$ be equal to $2 \cdot 10^{-5}$. This parameter is chosen for average job durations for equilibrium values of effort to be large enough. Table 1 presents the calibration for the benchmark case. In Table 2 , the comparison of equilibrium and social welfare outcomes in asymmetric information case, 


\begin{tabular}{c|c|l} 
Variable & Value & Explanation \\
\hline$n_{L}$ & 50 & Number of actual contacts of type $L$ workers \\
$n_{H}$ & 90 & Number of actual contacts of type $H$ workers \\
$\operatorname{Pr}\left(n_{L}\right)$ & 0.5 & The share of type $L$ workers \\
$r$ & 0.01 & Annual interest rate of $2 \%$ \\
$z$ & 0.5 & Unemployment benefit \\
$\sigma_{\epsilon}$ & 10 & Standard deviation for the firms' error \\
$\delta(0)$ & $1 / 5$ & Average job duration of 2.5 years (without effort) \\
$k_{0}$ & $2 \cdot 10^{-5}$ & $\delta(g)$ is close to the minimal for equilibrium effort values \\
$c$ & 0.5 & Vacancy cost \\
$\gamma$ & 1 & Degree of network homophily \\
$a$ & 0.5 & The rate of hearing about job openings by employees \\
$y$ & 1 & Workers' productivity \\
\hline
\end{tabular}

Table 1: Values of the model parameters

perfect information case and the case of a full information asymmetry is presented.

In the asymmetric information case, the separation rate $\delta\left(g_{L H}\right)$ is equal to 0.12069 corresponding to the job duration of $1 /(2 \cdot 0.12069)=4.14285$ years. The separation rate $\delta\left(g_{L}\right)$ is larger and is equal to 0.12922 , which corresponds to the job duration of $1 /(2 \cdot 0.12922)=3.86937$ years. The separation rate $\delta\left(g_{H}\right)$ is the largest and is equal to 0.13188 corresponding to the job duration of $1 /(2 \cdot 0.13188)=3.79139$ years. These high effort levels will naturally cause low overall number of unemployed and a large amount of vacancies ${ }^{12}$.

For the case of the full information asymmetry, the wage offered is in between the low and high wages in the asymmetric and perfect information cases. The overall social welfare is the biggest in the asymmetric information case and the smallest in the perfect information case. This may seem counterintuitive, since the asymmetric information case should naturally be in between of the two extreme cases. In the next subsection, the reasons for this will be discussed.

\begin{tabular}{l|c|c|c} 
Variable & Asymmetric & Perfect & Full asymmetry \\
\hline Low wage & 0.84533 & 0.83732 & 0.85122 \\
High wage & 0.85829 & 0.8699 & 0.85122 \\
Type- $L$ reservation wage & 0.8305 & 0.82157 & 0.83481 \\
Type- $H$ reservation wage & 0.84616 & 0.85784 & 0.83946 \\
Effort of low types at low wage & 7.50096 & 7.76799 & 7.95924 \\
Effort of low types at high wage & 10.79608 & - & - \\
Effort of high types & 6.67079 & 6.64786 & 6.55044 \\
Overall unemployment rate & $3.49426 \%$ & $3.42372 \%$ & $3.46373 \%$ \\
Unemployment rate of low types & $4.08832 \%$ & $4.02538 \%$ & $4.02738 \%$ \\
Unemployment rate of high types & $2.93084 \%$ & $2.82206 \%$ & $2.90009 \%$ \\
Threshold value of the signal & 61.77651 & - & - \\
Number of vacancies & 0.26662 & 0.26874 & 0.26752 \\
Overall social welfare & 0.8481 & 0.8475 & 0.8479 \\
\hline
\end{tabular}

Table 2: Comparison of equilibrium and social optimum outcomes in asymmetric information case, perfect information case and the case of a full information asymmetry

\footnotetext{
${ }^{12}$ The average unemployment rate in the United States in the recent years is $8.7 \%$ (BLS, 2009-2013). In addition, Elsby et al. (2013) report that, for OECD countries, the unemployment rate varies between $3.3 \%$ for Japan and $15.4 \%$ for Spain in 1968-2009.
} 


\subsection{Comparative statics}

The most important comparative statics question in this model is what happens with the change of $\sigma_{\epsilon}$ ? Consider the case of $\sigma_{\epsilon}$ changing from 5 to 10 . The signal distributions in the cases of $\sigma_{\epsilon}$ equal to 5 and 10 are illustrated on figure 1.
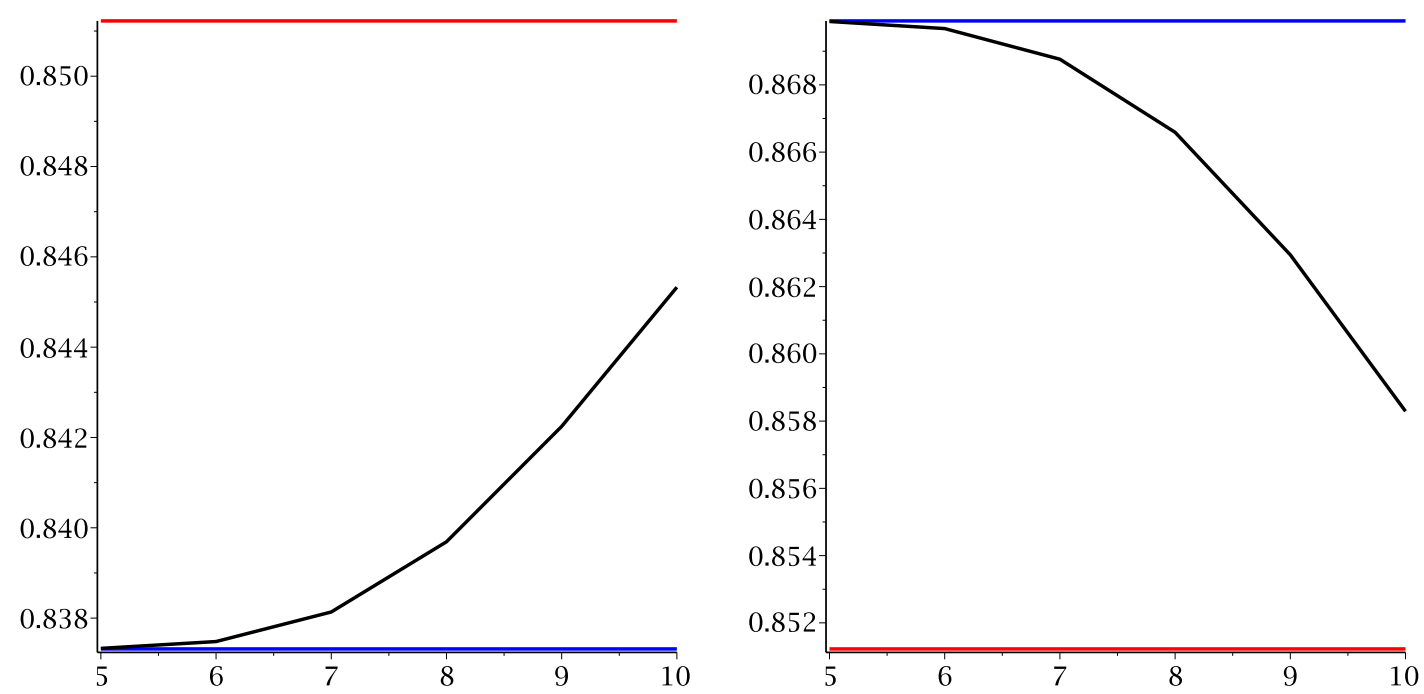

Figure 2: Left panel: Change in $w_{L}$ (black) with the increase in $\sigma_{\epsilon}, w_{L}^{1}$ (blue) and $w^{0}$ (red). Right panel: Change in $w_{H}$ (black) with the increase in $\sigma_{\epsilon}, w_{H}^{1}$ (blue) and $w^{0}$ (red).

The threshold number of contacts $\bar{n}^{\prime}$ decreases from 68.93801 to 61.77651 . Therefore, the probability to hire a low type worker at the low wage after a match, $\operatorname{Pr}\left(n^{\prime} \leq \bar{n}^{\prime} \mid n_{L}\right)$, decreases from 0.97087 to 0.88053 . Similarly, the probability not to hire a high type worker after a match, $\operatorname{Pr}\left(n^{\prime} \leq \bar{n}^{\prime} \mid n_{H}\right)$, decreases slightly from 0.01759 to 0.00238 as the change in $\bar{n}^{\prime}$ has the smaller effect in this case.

Changes in wage contracts and reservation wages are illustrated on figures 2 and 3, respectively. The wage contract $w_{L}\left(w_{H}\right)$ increases (decreases) from the value very close to $w_{L}^{1}\left(w_{H}^{1}\right)$ to the value close to $w^{0}$ and the reservation wage $r U_{L}\left(r U_{H}\right)$ increases (decreases) from the value very close to $r U_{L}^{1}\left(r U_{H}^{1}\right)$ to the value close to $r U_{L}^{0}\left(r U_{H}^{0}\right)$.

This is intuitive, as a larger uncertainty of firms makes low types better off in terms of reservation wages, and therefore, in wages since the probability of a low type to be considered as a high type is higher and they always accept. High types are worse off in terms of wages since they have to accept more offers competing with low types more which leads also to lower reservation wages.

Changes in effort levels are illustrated on figure 4. The effort level $g_{L}$ is always larger than $g_{H}$. Therefore, $J_{L}>J_{H}$, and firms will always get more profit from more low type workers employed.

The effort levels of low types, $g_{L}$ and $g_{L H}$, decrease and the effort level of high types, $g_{H}$, first increases and then decreases.

Intuitively, as the firms uncertainty increases, high type workers will be more interested in exerting a higher effort level to increase the duration of a match, otherwise, when unemployed, they will compete with low types more often. On the other hand, their wage will decrease, which 
has a negative effect on effort. The latter effect dominates when a firm's uncertainty is already large.
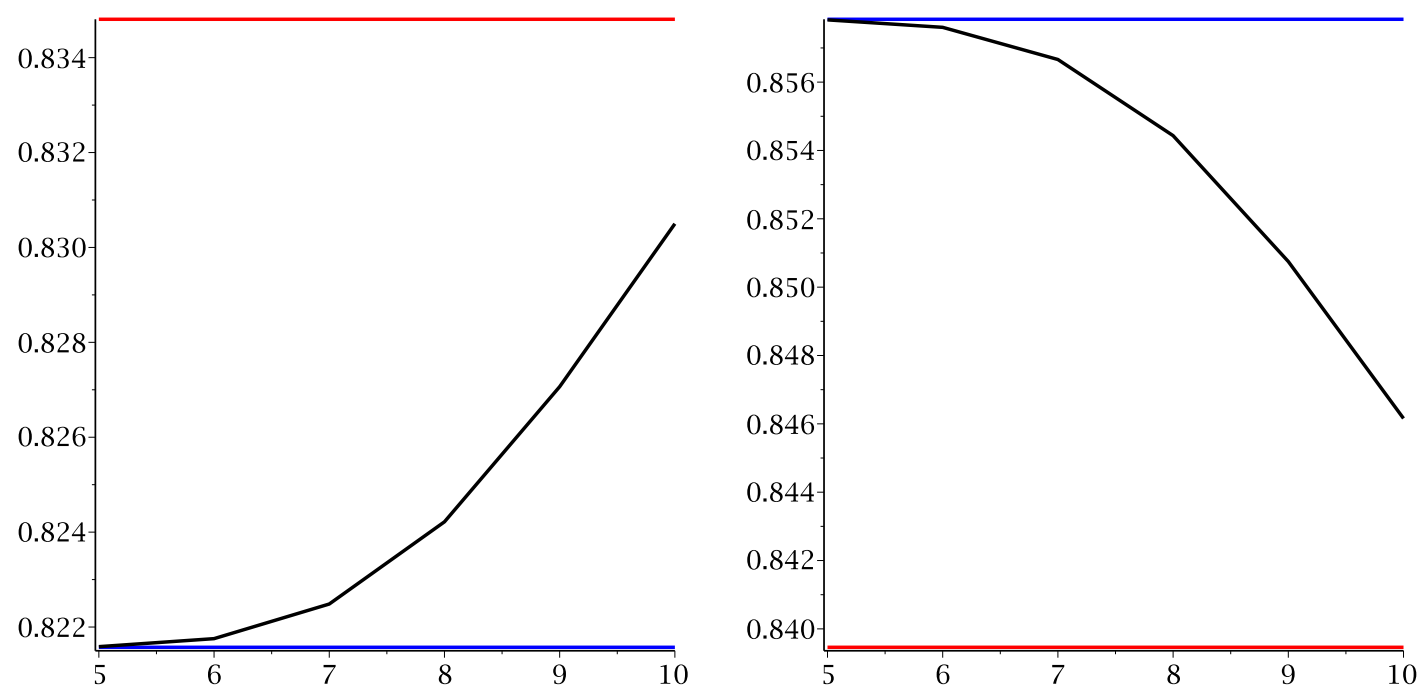

Figure 3: Left panel: Change in $r U_{L}$ (black) with the increase in $\sigma_{\epsilon}, r U_{L}^{1}$ (blue) and $r U_{L}^{0}$ (red). Right panel: Change in $r U_{H}$ (black) with the increase in $\sigma_{\epsilon}, r U_{H}^{1}$ (blue), $r U_{H}^{0}$ (red).

On the contrary, low types will be less concerned about loosing the job and exert less effort. This effect dominates the effect of a wage increase.

From the pictures it can be seen that the change in $g_{L H}$ is much larger than in $g_{L}$ and $g_{H}$. The change in $g_{L}$ is naturally larger than the change in $g_{H}$ as $\bar{n}^{\prime}$ decreases.

Both unemployment rates, $\mu_{L}$ and $\mu_{H}$, increase from the values very close to $\mu_{L}^{1}$ and $\mu_{H}^{1}$. This is illustrated on figure 5 .
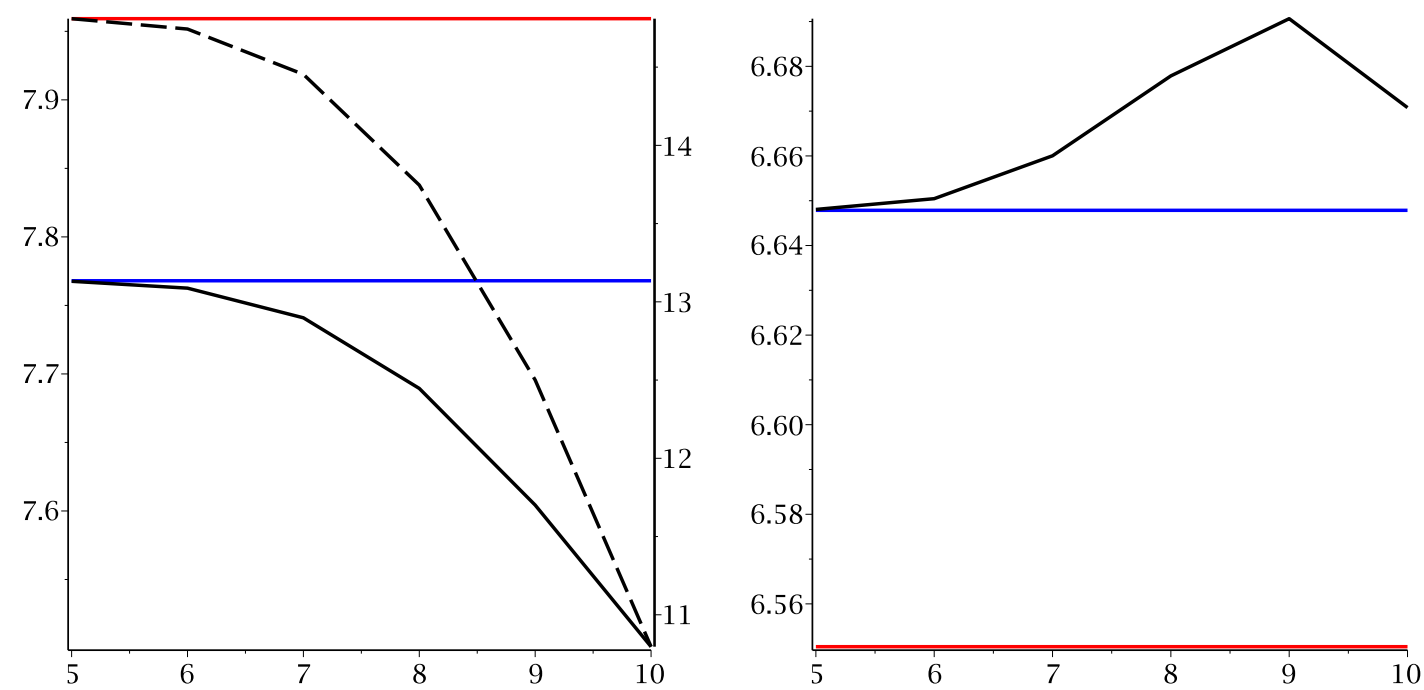

Figure 4: Left panel: Change in $g_{L}$ (solid) and in $g_{L H}$ (dashed, right axis) (black) with the increase in $\sigma_{\epsilon}, g_{L}^{1}$ (blue), $g_{L}^{0}$ (red). Right panel: Change in $g_{H}$ (black) with the increase in $\sigma_{\epsilon}$, $g_{H}^{1}$ (blue), $g_{H}^{0}$ (red).

The firms' profit per low type worker employed at the low (high) wage, $J_{L},\left(J_{L H}\right)$ decreases 
(increases slightly) from 1.17521 to 1.111 (from 1.05771 to 1.08431). On the other hand, the firms' profit per high type worker, $J_{H}$, increases from 0.9166 to 0.9988 .

In order to check whether offering of two wage contracts is indeed an equilibrium strategy of firms let us suppose that one firm deviates and offers either the wage $r U_{L}<\tilde{w}_{L}<r U_{H}$ or $\tilde{w}_{H}>r U_{H}$ to both types.

More precisely, when a firm adopts the strategy of two wage contracts $w_{L}$ and $w_{H}$ considered in the model, it receives the following expected profit from hiring a worker as in the maximization problem (6):

$$
J^{e x p}=\beta \operatorname{Pr}\left(n^{\prime} \leq \bar{n}^{\prime} \mid n_{L}\right) J_{L}+\beta \operatorname{Pr}\left(n^{\prime}>\bar{n}^{\prime} \mid n_{L}\right) J_{L H}+(1-\beta) \operatorname{Pr}\left(n^{\prime}>\bar{n}^{\prime} \mid n_{H}\right) J_{H}
$$
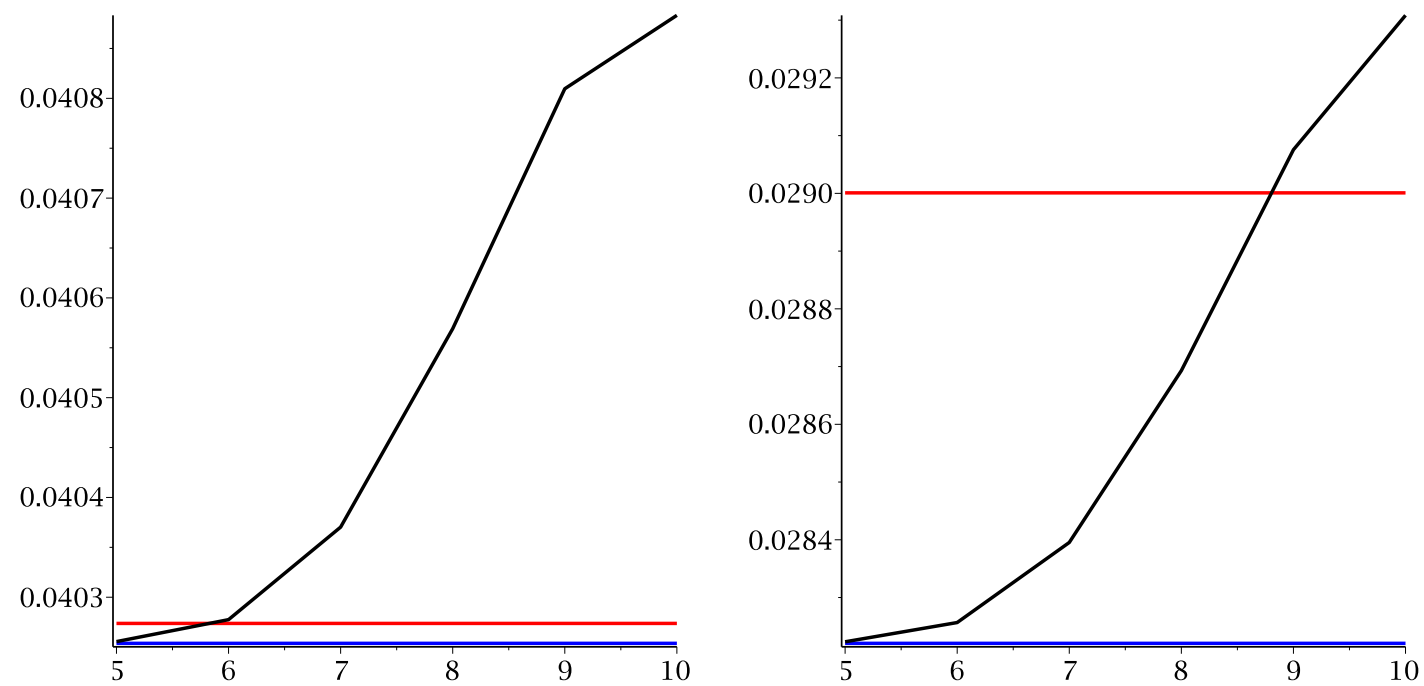

Figure 5: Left panel: Change in $\mu_{L}$ (black) with the increase in $\sigma_{\epsilon}, \mu_{L}^{1}$ (blue) and $\mu_{L}^{0}$ (red). Right panel: Change in $\mu_{H}$ (black) with the increase in $\sigma_{\epsilon}, \mu_{H}^{1}$ (blue) and $\mu_{H}^{0}$ (red).

On the contrary, the expected profit from hiring a worker when a firm deviates to offering either $\tilde{w}_{L}$ or $\tilde{w}_{H}$ is, respectively:

$$
J_{L}^{e x p}=\beta \max _{\tilde{w}_{L}} \tilde{J}_{L} \quad J_{H}^{e x p}=\max _{\tilde{w}_{H}}\left\{\beta \tilde{J}_{L H}+(1-\beta) \tilde{J}_{H}\right\}
$$

where $\tilde{J}_{L}=\frac{y-\tilde{w}_{L}}{r+\delta\left(\tilde{g}_{L}\right)}, \tilde{J}_{L H}=\frac{y-\tilde{w}_{H}}{r+\delta\left(\tilde{g}_{L H}\right)}$ and $\tilde{J}_{H}=\frac{y-\tilde{w}_{H}}{r+\delta\left(\tilde{g}_{H}\right)}$.

In the first maximization problem, the wage $\tilde{w}_{L}$ can be found analogously to $w_{L}^{1}$ from the Proposition 1 and is numerically equivalent to $w_{L}$ from the maximization problem (6) and, therefore, the firm receives $J_{L}>J_{L H}$ instead of $J_{L H}$ and looses $(1-\beta) \operatorname{Pr}\left(n^{\prime}>\bar{n}^{\prime} \mid n_{H}\right) J_{H}$ since only low types accept.

In the second maximization problem, the wage $\tilde{w}_{H}$ can be found analogously to $w^{0}$ from the Proposition 2.

From the figure 6 it can be seen that the strategy of offering two contracts is indeed the optimal one for firms for $\sigma_{\epsilon}$ from 5 to 10 .

The job-finding rate $\lambda_{L}$ decreases from 2.7929 to 2.73947 and the job-finding rate $\lambda_{H}$ decreases from 4.27473 to 4.1116 . The job-filling rate $q_{L}$ increases from 0.20918 to 0.21004 and 
the job-filling rate $q_{H}$ increases from 0.22447 to 0.22599 .

Changes in the income levels of low and high type workers are illustrated on figure $7 . \Lambda_{W L}$ naturally increases from the value very close to $\Lambda_{W L}^{1}$ and leads to $\Lambda_{W L}^{0}$. On the other hand, $\Lambda_{W H}$ decreases starting from the value very close to $\Lambda_{W H}^{1}$ and leads to $\Lambda_{W H}^{0}$, which is also intuitive.

The change in the average income of both worker types is illustrated on figure 8 (left panel). It decreases from the value very close to $\Lambda_{W}^{1}$ and naturally leads to $\Lambda_{W}^{0}$ as $\Lambda_{W H}$ decreases faster than $\Lambda_{W L}$ increases.

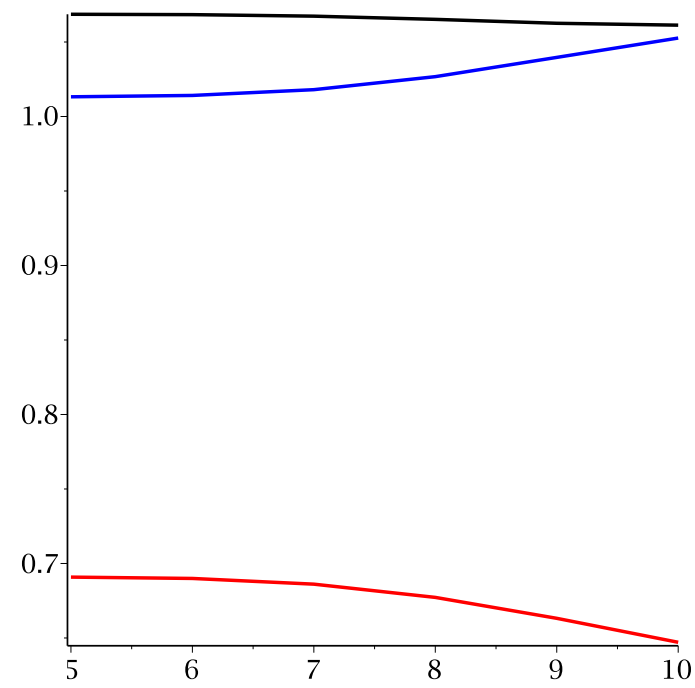

Figure 6: Change in $J^{e x p}$ (black), $J_{L}^{e x p}$ (red) and $J_{H}^{e x p}$ (blue) with the increase in $\sigma_{\epsilon}$.

The number of vacancies $v$ decreases from the value very close to $v^{1}$ (figure 9) (right panel). Intuitively, firms anticipate that in the asymmetric information case they will offer mismatched wages more often due to the larger probability of firms' mistakes leading to lower expected profits.

More precisely, when the firms' uncertainty increases, as it can be seen from the free-entry condition, there are two direct reinforcing effects influencing the number of vacancies mostly. Both the probability to employ low types at low wages after a match, $\operatorname{Pr}\left(n^{\prime} \leq \bar{n}^{\prime} \mid n_{L}\right)$, and the profit per hiring of such a worker, $J_{L}$, decrease. Other effects are rather small and are dominated.

The change in the overall average profits of firms, $\Lambda_{F}$, is illustrated on figure 8 (right panel). It increases from the value very close to $\Lambda_{F}^{1}$ and leads to $\Lambda_{F}^{0}$. This is intuitive as the number of vacancies decreases.

The overall social welfare, $\Lambda$, increases from the value close to $\Lambda^{1}$, leads to $\Lambda^{0}$ and increases further (figure 9 (left panel)) since $\Lambda_{F}$ increases faster than $\Lambda_{W}$ decreases.

As it was mentioned above, the increase in the overall social welfare with the increase in the uncertainty of firms may seem counterintuitive.

One of the reasons for this is that firms anticipate that expected profits from an open vacancy will decrease due to more mismatched wages offered and open less vacancies. So the information asymmetry turns out to be welfare improving as firms, by chance, will employ less workers which they would not like to employ.

Indeed, in the standard search theory with perfect information (for example, Pissarides 
(2000)), the social welfare is maximized when the workers' bargaining power is equal to the elasticity of the job-filling rate.

This result is known as the Hosios condition. Otherwise, when the workers' bargaining power is too low (high), firms will open too many (few) vacancies due to low (high) wages leading to more inefficiency.
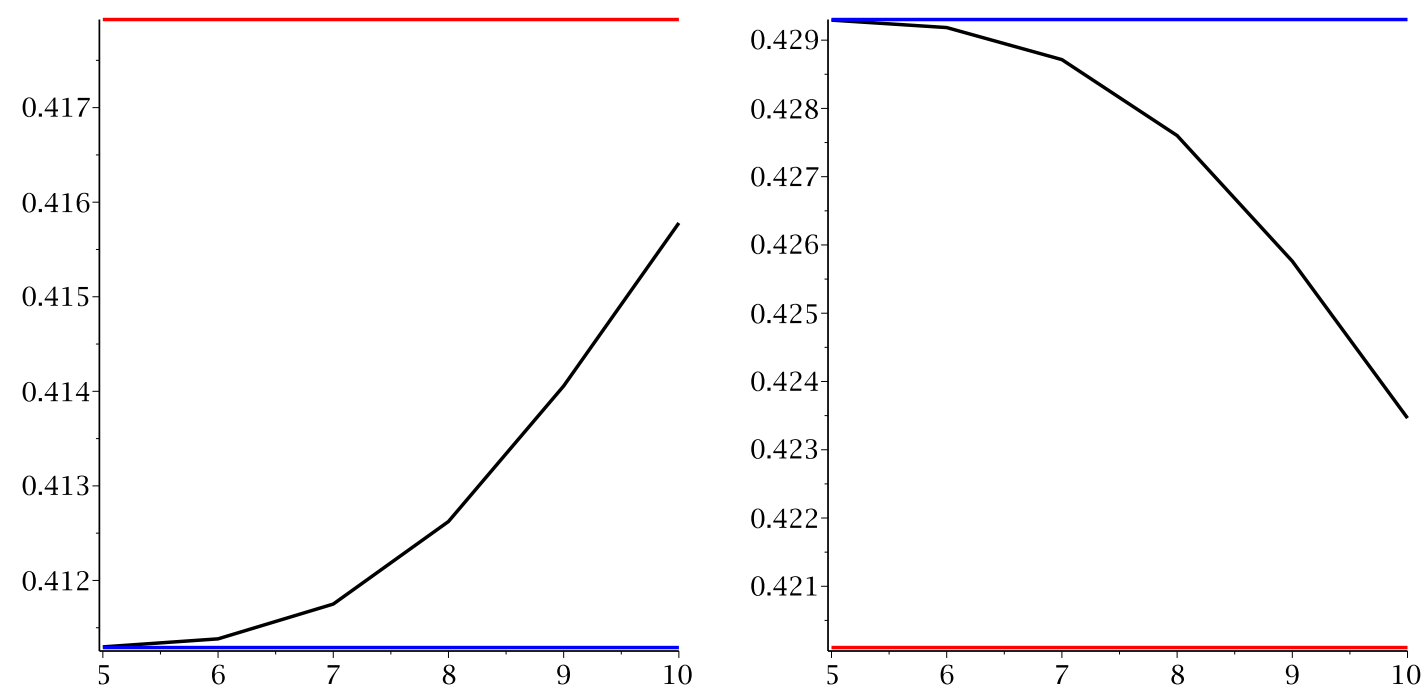

Figure 7: Left panel: Change in $\Lambda_{W L}$ (black) with the increase in $\sigma_{\epsilon}, \Lambda_{W L}^{1}$ (blue) and $\Lambda_{W L}^{0}$ (red). Right panel: Change in $\Lambda_{W H}$ (black) with the increase in $\sigma_{\epsilon}, \Lambda_{W H}^{1}$ (blue) and $\Lambda_{W H}^{0}$ (red).

Since in the present model the wage is offered only by firms, the workers' wages are relatively low. Moreover, the number of vacancies in the perfect information case is larger than in the asymmetric information case. This gives an intuition why the social welfare in the perfect information case is not the largest since the Hosios condition is not satisfied.
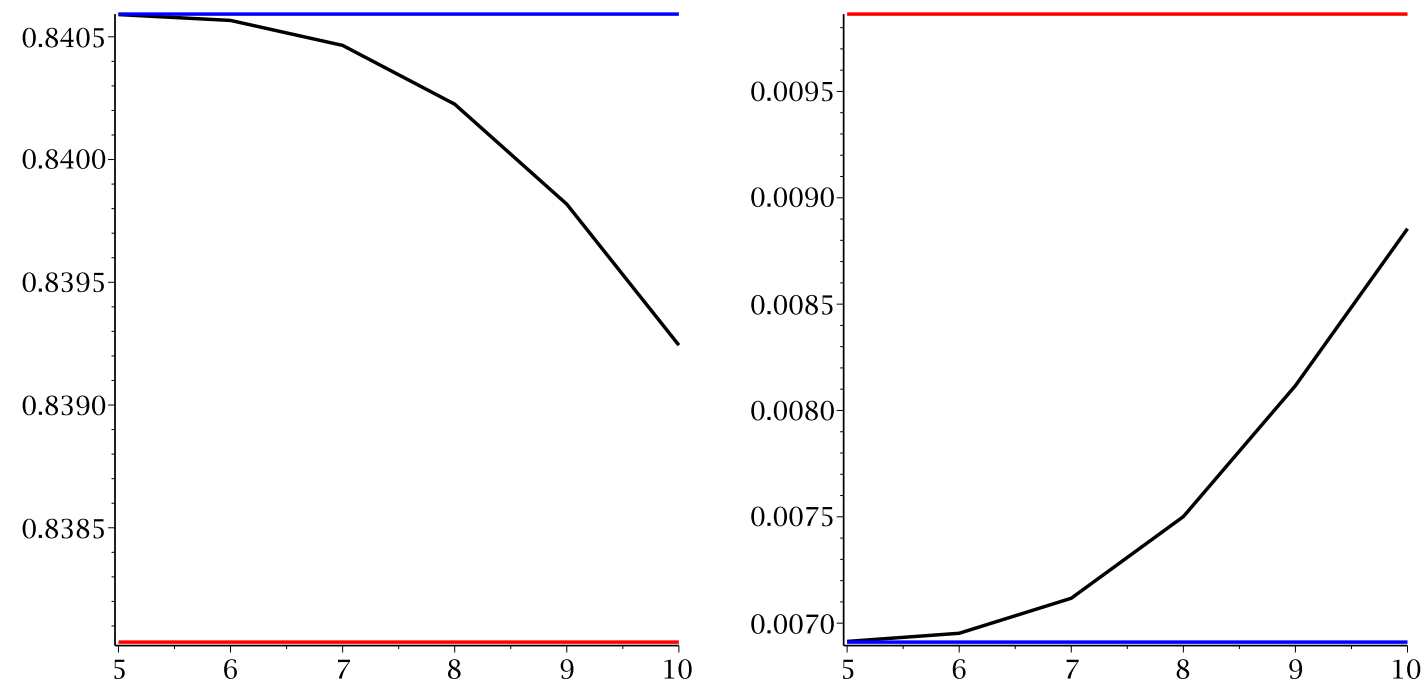

Figure 8: Left panel: Change in $\Lambda_{W}$ (black) with the increase in $\sigma_{\epsilon}, \Lambda_{W}^{1}$ (blue) and $\Lambda_{W}^{0}$ (red). Right panel: Change in $\Lambda_{F}$ (black) with the increase in $\sigma_{\epsilon}, \Lambda_{F}^{1}$ (blue) and $\Lambda_{F}^{0}$ (red). 
It is interesting to compare this finding to the conclusion of Montgomery (1991) that social contacts use leads to a higher level of social welfare due to a lower mismatch between firms and workers as referrals reveal the quality of the match. In the present paper, it is the higher level of mismatched wages offered which contributes to the increase in the welfare.
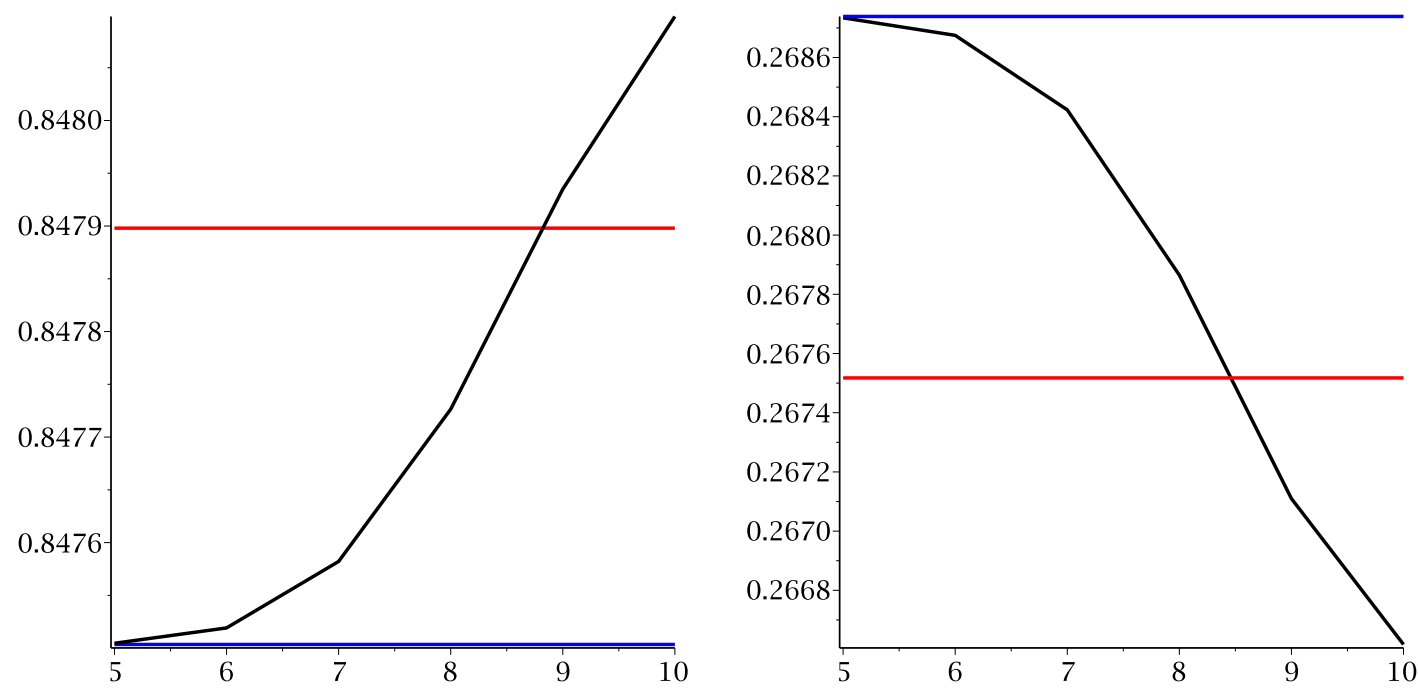

Figure 9: Left panel: Change in $\Lambda$ (black) with the increase in $\sigma_{\epsilon}, \Lambda^{1}$ (blue) and $\Lambda^{0}$ (red). Right panel: Change in $v$ (black) with the increase in $\sigma_{\epsilon}, v^{1}$ (blue) and $v^{0}$ (red).

\section{Conclusions}

In this paper, the random matching model is proposed, in which firms face uncertainty about workers' number of social contacts defining their outside options in the sense of job search through referrals. This number is known perfectly to workers who are homogeneous in all other characteristics. Wages are assumed to be offered only by firms in a form of a take-it-or-leave-it offer during the interview with a job seeker and a worker accepts a wage contract if it is at least as large as her outside options. In addition, wages are set in such a way that workers will have an incentive to exert effort. Firms also check the worker's public number of non-fictitious social contacts in the Social Network Systems in the Internet. This number is assumed to be correlated to the actual number of social contacts and, therefore, serves as a noisy signal of the social capital for firms. For simplicity, only two worker types are considered in the model: with low and high social capital.

The semi-separating equilibrium with two wage contracts, which follows the threshold rule, is considered. In this equilibrium, the higher wage will be accepted by both worker types and the lower wage only by the low types leading only to partial separation. The model generates a positive relationship between the number of contacts in the social media and the wage offered by firms in the equilibrium. Thus, there will be a wage dispersion between equally productive workers with different number of contacts in the Social Network System, which extends the classical result on wage dispersion with respect to the signal in the literature on uncertainty about the worker's productivity. Therefore, this model gives an additional explanation for the empirically observed wage dispersion between workers with equal productivity. 
Moreover, the comparative statics w.r.t. firms' uncertainty level was conducted and the equilibrium outcomes of this model were compared numerically with the two extreme cases: the case of a perfect information and the case of a full information asymmetry. It was found that (reservation) wages, the overall average firms' profit and average workers' income levels in the asymmetric information case lead to those arising in the case of a full information asymmetry as the firms' uncertainty level increases. Thus, naturally, the equilibrium outcomes in the asymmetric information case are in between of these two extreme cases. However, the overall social welfare in the asymmetric information case is increasing which may seem counterintuitive.

One of the reasons for this is that firms anticipate that expected profits from an open vacancy will decrease due to more mismatched wages offered and open less vacancies thus decreasing their overall cost and leading to the welfare increase. So the information asymmetry turns out to be welfare improving as firms, by chance, will employ less workers which they would not like to employ. It is also interesting to compare this finding to the conclusion of Montgomery (1991) that social contacts use leads to a higher level of social welfare due to a lower mismatch between firms and workers as referrals reveal the quality of the match. In the present paper, it is a higher level of mismatched wages offered that contributes to the increase in the welfare.

\section{Acknowledgements}

I am grateful to Anna Zaharieva, Herbert Dawid, Andrey Launov, Oliver Fabel as well as to the participants of the Networks Seminar and the Labour Economics Seminar at the Bielefeld University for the useful comments and suggestions.

\section{Appendix}

\section{Appendix I. Proof of Proposition 1:}

In order to determine the wage $w_{i}^{1}, i=L, H$ offered by firms, let us find the first order condition to the firm's maximization problem (18), taking first into account that the optimal effort $g_{i}^{1}$ is a function of $w_{i}^{1}-r U_{i}^{1}$, i.e.:

$$
w_{i}^{1}-r U_{i}^{1}=k\left(g_{i}^{1}\right)-\frac{k^{\prime}\left(g_{i}^{1}\right)}{\delta^{\prime}\left(g_{i}^{1}\right)}\left(r+\delta\left(g_{i}^{1}\right)\right)
$$

Thus, by differentiating this equation w.r.t. $g_{i}^{1}$ taking $U_{i}^{1}$ parametrically, the inverse of $\frac{\partial g_{i}^{1}}{\partial\left(w_{i}^{1}-r U_{i}^{1}\right)}$ can be found:

$$
\frac{\partial\left(w_{i}^{1}-r U_{i}^{1}\right)}{\partial g_{i}^{1}}=-\frac{\left(k^{\prime \prime}\left(g_{i}^{1}\right) \delta^{\prime}\left(g_{i}^{1}\right)-\delta^{\prime \prime}\left(g_{i}^{1}\right) k^{\prime}\left(g_{i}^{1}\right)\right)}{\left(\delta^{\prime}\left(g_{i}^{1}\right)\right)^{2}}\left(r+\delta\left(g_{i}^{1}\right)\right)
$$

Thus, the first order conditions to the problem (18) can be written as follows:

$$
\frac{-\left(r+\delta\left(g_{i}^{1}\right)\right)+\left(y-w_{i}^{1}\right) \delta^{\prime}\left(g_{i}^{1}\right) \frac{\left(\delta^{\prime}\left(g_{i}^{1}\right)\right)^{2}}{\left(r+\delta\left(g_{i}^{1}\right)\right)\left(k^{\prime \prime}\left(g_{i}^{1}\right) \delta^{\prime}\left(g_{i}^{1}\right)-\delta^{\prime \prime}\left(g_{i}^{1}\right) k^{\prime}\left(g_{i}^{1}\right)\right)}}{\left(r+\delta\left(g_{i}^{1}\right)\right)^{2}}=0
$$


From this equation, the expression for the optimal wage $w_{i}^{1}$ can be obtained:

$$
w_{i}^{1}=y-\frac{\left(r+\delta\left(g_{i}^{1}\right)\right)^{2}\left(k^{\prime \prime}\left(g_{i}^{1}\right) \delta^{\prime}\left(g_{i}^{1}\right)-\delta^{\prime \prime}\left(g_{i}^{1}\right) k^{\prime}\left(g_{i}^{1}\right)\right)}{\left(\delta^{\prime}\left(g_{i}^{1}\right)\right)^{3}}
$$

Note that $\delta^{\prime}(g)=-\left(2\left(d_{0}+\sqrt{g}\right)^{2} \sqrt{g}\right)^{-1}$.

Since for $r \rightarrow 0$ and $d_{0}=0,\left|\frac{k^{\prime}(g)}{\delta^{\prime}(g)}\right|(r+\delta(g))+k(g)$ is a quadratic function, the optimal workers' effort function for a given wage is close to the square root of wage.

Appendix II. Proof of Proposition 2: Taking into account the derivatives of $g_{L}^{0}$ and $g_{H}^{0}$, which can be found as in the proof of Proposition 1, the first order condition for the problem (25) can be then written as follows:

$$
\begin{gathered}
\beta^{0} \cdot \frac{-\left(r+\delta\left(g_{L}^{0}\right)\right)+\left(y-w^{0}\right) \delta^{\prime}\left(g_{L}^{0}\right) \frac{\left(\delta^{\prime}\left(g_{L}^{0}\right)\right)^{2}}{\left(r+\delta\left(g_{L}^{0}\right)\right)\left(k^{\prime \prime}\left(g_{L}^{0}\right) \delta^{\prime}\left(g_{L}^{0}\right)-\delta^{\prime \prime}\left(g_{L}^{0}\right) k^{\prime}\left(g_{L}^{0}\right)\right)}}{\left(r+\delta\left(g_{L}^{0}\right)\right)^{2}}+ \\
+\left(1-\beta^{0}\right) \cdot \frac{-\left(r+\delta\left(g_{H}^{0}\right)\right)+\left(y-w^{0}\right) \delta^{\prime}\left(g_{H}^{0}\right) \frac{\left(\delta^{\prime}\left(g_{H}^{0}\right)\right)^{2}}{\left(r+\delta\left(g_{H}^{0}\right)\right)\left(k^{\prime \prime}\left(g_{H}^{0}\right) \delta^{\prime}\left(g_{H}^{0}\right)-\delta^{\prime \prime}\left(g_{H}^{0}\right) k^{\prime}\left(g_{H}^{0}\right)\right)}}{\left(r+\delta\left(g_{H}^{0}\right)\right)^{2}}=0
\end{gathered}
$$

Rewriting this equation leads to:

$$
\begin{gathered}
\beta^{0}\left(r+\delta\left(g_{H}^{0}\right)\right)^{2} \cdot\left[-\left(r+\delta\left(g_{L}^{0}\right)\right)+\left(y-w^{0}\right) \frac{\left(\delta^{\prime}\left(g_{L}^{0}\right)\right)^{3}}{\left(r+\delta\left(g_{L}^{0}\right)\right)\left(k^{\prime \prime}\left(g_{L}^{0}\right) \delta^{\prime}\left(g_{L}^{0}\right)-\delta^{\prime \prime}\left(g_{L}^{0}\right) k^{\prime}\left(g_{L}^{0}\right)\right)}\right]+ \\
+\left(1-\beta^{0}\right)\left(r+\delta\left(g_{L}^{0}\right)\right)^{2} \cdot\left[-\left(r+\delta\left(g_{H}^{0}\right)\right)+\left(y-w^{0}\right) \frac{\left(\delta^{\prime}\left(g_{H}^{0}\right)\right)^{3}}{\left(r+\delta\left(g_{H}^{0}\right)\right)\left(k^{\prime \prime}\left(g_{H}^{0}\right) \delta^{\prime}\left(g_{H}^{0}\right)-\delta^{\prime \prime}\left(g_{H}^{0}\right) k^{\prime}\left(g_{H}^{0}\right)\right)}\right]=0
\end{gathered}
$$

Simplifying this equation further gives the following expression:

$$
\begin{gathered}
\beta^{0}\left(r+\delta\left(g_{H}^{0}\right)\right)^{3}\left(k^{\prime \prime}\left(g_{H}^{0}\right) \delta^{\prime}\left(g_{H}^{0}\right)-\delta^{\prime \prime}\left(g_{H}^{0}\right) k^{\prime}\left(g_{H}^{0}\right)\right) \cdot \\
\cdot\left[-\left(r+\delta\left(g_{L}^{0}\right)\right)^{2}\left(k^{\prime \prime}\left(g_{L}^{0}\right) \delta^{\prime}\left(g_{L}^{0}\right)-\delta^{\prime \prime}\left(g_{L}^{0}\right) k^{\prime}\left(g_{L}^{0}\right)\right)+\left(y-w^{0}\right)\left(\delta^{\prime}\left(g_{L}^{0}\right)\right)^{3}\right]+ \\
+\left(1-\beta^{0}\right)\left(r+\delta\left(g_{L}^{0}\right)\right)^{3}\left(k^{\prime \prime}\left(g_{L}^{0}\right) \delta^{\prime}\left(g_{L}^{0}\right)-\delta^{\prime \prime}\left(g_{L}^{0}\right) k^{\prime}\left(g_{L}^{0}\right)\right) \cdot \\
\cdot\left[-\left(r+\delta\left(g_{H}^{0}\right)\right)^{2}\left(k^{\prime \prime}\left(g_{H}^{0}\right) \delta^{\prime}\left(g_{H}^{0}\right)-\delta^{\prime \prime}\left(g_{H}^{0}\right) k^{\prime}\left(g_{H}^{0}\right)\right)+\left(y-w^{0}\right)\left(\delta^{\prime}\left(g_{H}^{0}\right)\right)^{3}\right]=0
\end{gathered}
$$

The last expression can be rewritten also as:

$$
\begin{gathered}
\beta^{0} x^{0}\left(g_{H}^{0}\right)\left[-\frac{x^{0}\left(g_{L}^{0}\right)}{r+\delta\left(g_{L}^{0}\right)}+\left(y-w^{0}\right)\left(\delta^{\prime}\left(g_{L}^{0}\right)\right)^{3}\right]+ \\
+\left(1-\beta^{0}\right) x^{0}\left(g_{L}^{0}\right)\left[-\frac{x\left(g_{H}^{0}\right)}{r+\delta\left(g_{H}^{0}\right)}+\left(y-w^{0}\right)\left(\delta^{\prime}\left(g_{H}^{0}\right)\right)^{3}\right]=0
\end{gathered}
$$

From this equation it is easy to receive the optimal $w^{0}$ :

$$
w^{0}=y-\frac{x^{0}\left(g_{L}^{0}\right) x^{0}\left(g_{H}^{0}\right) \cdot\left[\frac{\beta^{0}}{r+\delta\left(g_{L}^{0}\right)}+\frac{\left(1-\beta^{0}\right)}{r+\delta\left(g_{H}^{0}\right)}\right]}{\beta^{0}\left(\delta^{\prime}\left(g_{L}^{0}\right)\right)^{3} x^{0}\left(g_{H}^{0}\right)+\left(1-\beta^{0}\right)\left(\delta^{\prime}\left(g_{H}^{0}\right)\right)^{3} x^{0}\left(g_{L}^{0}\right)}
$$




\section{References}

[1] Acemoglu D., 1995. Asymmetric Information, Bargaining, and Unemployment Fluctuations. International Economic Revew 36 (4), 1003-1024.

[2] Addison J. T., Portugal P., 2002. Job Search Methods and Outcomes. Oxford Economic Papers 54 (3), 505-533.

[3] Akerlof G. A., 1970. The Market for "Lemons": Quality Uncertainty and the Market Mechanism. The Quarterly Journal of Economics 84 (3), 488-500.

[4] Alonso R. 2014. Recruitment and selection in organizations. USC Marshall School of Business Research Paper Series.

[5] Bentolila, S., Michelacci, C., Suarez, J., 2010. Social Contacts and Occupational Choice. Economica 77, 20-45.

[6] Bohnert D., Ross W. H., 2010. The influence of social networking web sites on the evaluation of job candidates. Cyberpsychology, Behavior, and Social Networking 13 (3), 341-347.

[7] Bruegemann B., Moscarini G., 2010. Rent Rigidity, asymmetric information, and volatility bounds in labor markets. Review of Economic Dynamics 13, 575-596.

[8] Bureau of Labor Statistics. www.bls.gov.

[9] Cahuc P., Fontaine F., 2009. On the Efficiency of Job Search with Social Networks. Journal of Public Economic Theory 11 (3), 411-439.

[10] CarreerBuilder.com, 2012. What are employers discovering about candidates through social media? http://thehiringsite.careerbuilder.com/2012/04/20/what-are-employersseeking-and-finding-out-about-candidates-through-social-media/.

[11] CarreerBuilder.com, 2013. More Employers Finding Reasons Not to Hire Candidates on Social Media, Finds CareerBuilder Survey. http://www.careerbuilder.com/share/aboutus/pressreleasesdetail.aspx?sd $=6 / 26 / 2013 \&$ id $=$ pr766\&ed $=12 / 31 / 2013$.

[12] Cingano F., Rosolia A., 2012. People I Know: Job Search and Social Networks. Journal of Labor Economics 30 (2), 291-332.

[13] Dao N.H., 2009. Asymmetric information, wage dispersion and unemployment fluctuations. Working paper. University of Montreal.

[14] Delacroix A., Wasmer E., 2009. Layoff costs and efficiency with asymmetric information. IZA Discussion Papers No. 4524.

[15] Delattre, E., Sabatier, M., 2007. Social Capital and Wages: An Econometric Evaluation of Social Networking's Effects. Labour 21, 209-236. 
[16] Ellison N. B., Steinfield C., Lampe C., 2011. Connection strategies: Social capital implications of Facebook-enabled communication practices. New Media and Society 13 (6), 873-892.

[17] Ellison N. B., Vitak J., Gray R., Lampe C., 2014. Cultivating Social Resources on Social Network Sites: Facebook Relationship Maintenance Behaviors and Their Role in Social Capital Processes. Journal of Computer-Mediated Communication 19 (4), 855-870.

[18] Elsby M.W. L., Hobijn B., Sahin A., 2013. Unemployment dynamics in OECD. The Review of Economics and Statistics 95 (2): 530-548.

[19] Fontaine F., 2008. Why Are Similar Workers Paid Differently? The Role of Social Networks. Journal of Economic Dynamics and Control 32(12), 3960-3977.

[20] Galenianos M., 2014. Hiring through Referrals. Journal of Economic Theory 152, 304-323.

[21] Gautier P. A., 2002. Unemployment and Search Externalities in a Model with Heterogeneous Jobs and Workers. Economica 69, 21-40.

[22] Gautier P. A., Teulings C. N., van Vuuren A., 2010. On-the-Job Search, Mismatch and Efficiency. Review of Economic Studies 77 (1), 245-272.

[23] Glitz A., 2013. Coworker Networks in the Labour Market. CESIfo Working paper No. 4250 .

[24] Goos M., Salomons A., 2007. Dangerous liaisons: a social network model for the gender wage gap. Discussion paper series, No. 07.22.

[25] Granovetter M., 1995. Getting a Job: A Study of Contacts and Careers. The University of Chicago Press.

[26] Guash J.L., Weiss A., 1980. Wages as Sorting Mechanisms in Competitive Markets with Asymmetric Information: A Theory of Testing. Review of Economic Studies 47 (4), 653664 .

[27] Guerrieri, V., Shimer, R., Wright, R., 2010. Adverse Selection in Competitive Search Equilibrium. Econometrica, 78: 1823-1862.

[28] Hagedorn M., Manovskii I., 2008. The Cyclical Behavior of Equilibrium Unemployment and Vacancies Revisited. The American Economic Review 98 (4), 1692-1706.

[29] Hall R., Milgrom P., 2008. The Limited Influence of Unemployment on the Wage Bargain. American Economic Review 98:4, 1653-1674.

[30] Hensvik L., Skans O.N., 2013. Social Networks, Employee Selection and Labor Market Outcomes. IFAU working paper, No. 2013:15.

[31] Hobijn B., Sahin A., 2009. Job-finding and Separation Rates in the OECD. Economics Letters 104 (3), 107-111. 
[32] Ioannides Y.M., Soetevent A. R., 2006. Wages and Employment in a Random Social Network with Arbitrary Degree Distribution. The American Economic Review 96 (2), $270-274$.

[33] Kennan J., 2010. Private Information, Wage Bargaining and Employment Fluctuations. Review of Economic Studies 77 (2), 633-664.

[34] Kugler A. D., 2003. Employee Referrals and Efficiency Wages. Labour Economics 10, 531556.

[35] Kugler A.D., Saint-Paul G., 2004. How Do Firing Costs Affect Worker Flows in a World with Adverse Selection? Journal of Labor Economics 22 (3), 553-584.

[36] Manant M., Pajak S., Soulie N., 2014. Do recruiters like it? Online social networks and privacy in hiring: a pseudo-randomized experiment. Working Paper. University of Paris Sud.

[37] Margolis D.N., Simonnet V., 2003. Educational Track, Networks and Labor Market Outcomes. IZA discussion paper No. 699.

[38] Michelacci C., Suarez J., 2006. Incomplete Wage Posting. Journal of Political Economy 114 (6), 1098-1123.

[39] Montgomery J.D., 1991. Social Networks and Labor-Market Outcomes: Toward an Economic Analysis. American Economic Review 81, 1408-1418.

[40] Montgomery J.D., 1992. Job Search and Network Composition: Implications of the Strength-Of-Weak-Ties Hypothesis. American Sociological Review 57 (5), 586-596.

[41] Mortensen D. T., Pissarides C.A., 1994. Job Creation and Job Destruction in the Theory of Unemployment. The Review of Economic Studies 61 (3), 397-415.

[42] Mortensen D., 2003. Why are similar workers paid differently? Cambridge: MIT Press.

[43] Myerson R.B., Satterthwaite M.A., 1983. Efficient Mechanisms for Bilateral Trading. Journal of economic theory 29, 265-281.

[44] OECD, 2013. Education at a Glance: OECD Indicators. OECD Publishing.

[45] Pelizzari M., 2010. Do Friends and Relatives Really Help in Getting a Good Job? Industrial and Labor Relations Review 63 (3), 494-510.

[46] Pew Research Center, 2014. Social Networking Fact Sheet. http://www.pewinternet.org/fact-sheets/social-networking-fact-sheet/.

[47] Pissarides C.A., 2000. Equilibrium unemployment theory. MIT Press.

[48] Pissarides C.A., 2009. The Unemployment Volatility Puzzle: is Wage Stickiness the Answer? Econometrica 77 (5), 1339-1369.

[49] Pistaferri L., 1999. Informal Networks in the Italian Labor Market. Giornale degli Economisti e Annali di Economia 58 (3-4), 355-375. 
[50] Rivera M.T., Soderstrom S.B., Uzzi B., 2010. Dynamics of Dyads in Social Networks: Assortative, Relational, and Proximity Mechanisms. Annual Review of Sociology 36, 91115.

[51] Roulin N., Bangerter A., 2013. Social Networking Websites in Personnel Selection. A Signaling Perspective on Recruiters and Applicants Perceptions. Journal of Personnel Psychology 12(3), 143-151.

[52] Rostila M., 2013. Social Capital and Health Inequality in European Welfare States. Palgrave Macmillan.

[53] Samuelson W., 1984. Bargaining under Asymmetric Information. Econometrica 52 (4), 995-1006.

[54] Shimer R., 2005. The Cyclical Behavior of Equilibrium Unemployment and Vacancies. The American Economic Review 95 (1), 25-49.

[55] Simon C. J., Warner J. T., 1992. Matchmaker, Matchmaker: The Effect of Old Boy Networks on Job Match Quality, Earnings, and Tenure. Journal of Labor Economics 10 (3), 306-330.

[56] Spence M., 1973. Job Market Signaling. The Quarterly Journal of Economics 87 (3), 355374.

[57] Staiger D., 1990. The Effect of Connections on the Wages and Mobility of Young Workers. Dissertation, MIT.

[58] Statista, 2014. Percentage of U.S. internet users who use Facebook in September 2014, by age group. http://www.statista.com/statistics/246221/share-of-us-internet-users-whouse-facebook-by-age-group/.

[59] Stupnytska Y., Zaharieva A., 2015. Explaining the U-shape of the referral hiring pattern in a search model with heterogeneous workers. Revise and Resubmit, Journal of Economic Behavior and Organization.

[60] Teulings C. N., Gautier P. A., 2004. The Right Man for the Job. Review of Economic Studies $71(2), 553-580$.

[61] Utz S., 2010. Show me your friends and I will tell you what type of person you are: How one's profile, number of friends, and type of friends influence impression formation on social network sites. Journal of Computer-Mediated Communication 15 (2), 314-335.

[62] Vicknair J., Elkersh D., Yancey K., Budden M., 2010. The use of social networking websites as a recruiting tool for employers. American Journal of Business Education 3 (11), 7-12.

[63] Zaharieva A., 2010. Working Effort and Endogenous Job Separations in Search Equilibrium. Working paper No. 2010-6. University of Konstanz. 